Landslides (2015) 12:1077-1095 DOl 10.1007/s10346-014-0521-x Received: 20 March 2014

Accepted: 22 September 2014

Published online: 6 November 2014

(c) The Author(s) 2014

This article is published with open access at Springerlink.com
Bayes Ahmed

\section{Landslide susceptibility mapping using multi-criteria evaluation techniques in Chittagong Metropolitan Area, Bangladesh}

Abstract Landslides are a common hazard in the highly urbanized hilly areas in Chittagong Metropolitan Area (CMA), Bangladesh. The main cause of the landslides is torrential rain in short period of time. This area experiences several landslides each year, resulting in casualties, property damage, and economic loss. Therefore, the primary objective of this research is to produce the Landslide Susceptibility Maps for CMA so that appropriate landslide disaster risk reduction strategies can be developed. In this research, three different Geographic Information Systembased Multi-Criteria Decision Analysis methods-the Artificial Hierarchy Process (AHP), Weighted Linear Combination (WLC), and Ordered Weighted Average (OWA) - were applied to scientifically assess the landslide susceptible areas in CMA. Nine different thematic layers or landslide causative factors were considered. Then, seven different landslide susceptible scenarios were generated based on the three weighted overlay techniques. Later, the performances of the methods were validated using the area under the relative operating characteristic curves. The accuracies of the landslide susceptibility maps produced by the AHP, WLC_1, WLC_2, WLC_3, OWA_1, OWA_2, and OWA_3 methods were found as $89.80,83.90,91.10,88.50,90.40,95.10$, and $87.10 \%$, respectively. The verification results showed satisfactory agreement between the susceptibility maps produced and the existing data on the 20 historical landslide locations.

Keywords Landslide Susceptibility Mapping (LSM) · Artificial Hierarchy Process (AHP) · Weighted Linear Combination (WLC) · Ordered Weighted Average (OWA) · Relative Operating Characteristic (ROC) • Geographic Information System (GIS)

\section{Introduction}

Chittagong Metropolitan Area (CMA) is highly vulnerable to landslide hazard, with an increasing trend of frequency and damage. Devastating landslides have hit CMA (Fig. 1) repeatedly in recent years (Table 1). The major recent landslide events were related to extreme rainfall intensities having short period of time. All the major landslide events occurred as a much higher rainfall amount compared to the monthly average. Moreover, rapid urbanization, increased population density, improper landuse, alterations in the hilly regions by illegally cutting the hills, indiscriminate deforestation, and agricultural practices are aggravating the landslide vulnerability in CMA (Khan et al. 2012).

In addition, there is no strict hill management policy within CMA. This has encouraged many informal settlements along the landslide-prone hill-slopes in Chittagong. These settlements are being considered as illegal by the formal authorities, while the settlers claim themselves as legal occupants. This is how there is acute land tenure conflict among the formal authorities, the settlers, and the local communities over the past few decades. This kind of conflict has also weakened the institutional arrangement for reducing the landslide vulnerability in Chittagong City (Ahammad 2009).

At this drawback, it is therefore essential to determine the landslide prone areas in CMA (Fig. 1b) so that appropriate landslide disaster risk reduction strategies can be developed. Producing up-to-date and accurate landslide susceptibility maps can ensure safety to people and property at risk and avoid extensive economic loss (Kavzoglu et al. 2013).

\section{Literary works on landslide susceptibility modelling}

Landslides are one of the most significant natural damaging disasters in hilly environments (Ayala et al. 2006). Social and economic losses due to landslides can be reduced by the means of effective planning and management (Rajakumar et al. 2007). Landslide hazard assessment is generally based on the concept that 'the present and the past are keys to the future'. This is why, most landslide hazard analyses take into account an up-to-date landslide inventory that represents the fundamental tool for identifying the hill-slope instability factors in triggering landslides (Lee and Sambath 2006).

Various geo-structural as well as causative-factor based approaches are already available for landslide susceptibility zoning. But Geographic Information System (GIS) modelling of landslide phenomena has taken precedence in recent time. Geospatial technologies like the use of GIS, Global Positioning System (GPS), and Remote Sensing (RS) are useful in the hazard assessment, risk identification, and disaster management for landslides. GPS is a space-based global navigation satellite system which provides the information of position and time anywhere in the world in all weather conditions (Akbar and Ha 2011). Previous studies showed the application of GPS for mapping and identifying landslide zones. GIS is used for data collection, storage, and analysis of processes where geographic information is involved. The use of GIS for landslide mapping is common in various studies. Remote sensing is the science in which information is acquired about the surface of earth without physically being in contact with it. RS is also used for monitoring and mapping of landslides (Akbar and Ha 2011).

Mapping the areas that are susceptible to landslides is essential for proper land use planning and disaster management for a particular locality or region. Throughout the years, different techniques and methods have been developed and applied in the literature for landslide susceptibility mapping. Landslide susceptibility maps can be produced using both the quantitative or qualitative approach (Park et al. 2013).

Qualitative maps weight each factors affecting the landslides based on the practical experience and expertise of the researcher (Park et al. 2013). Qualitative methods simply portray the hazard zoning in descriptive terms (Guzzetti et al. 1999). But because of the developments in computer programming and geospatial technologies, quantitative techniques have become popular in recent decades. 

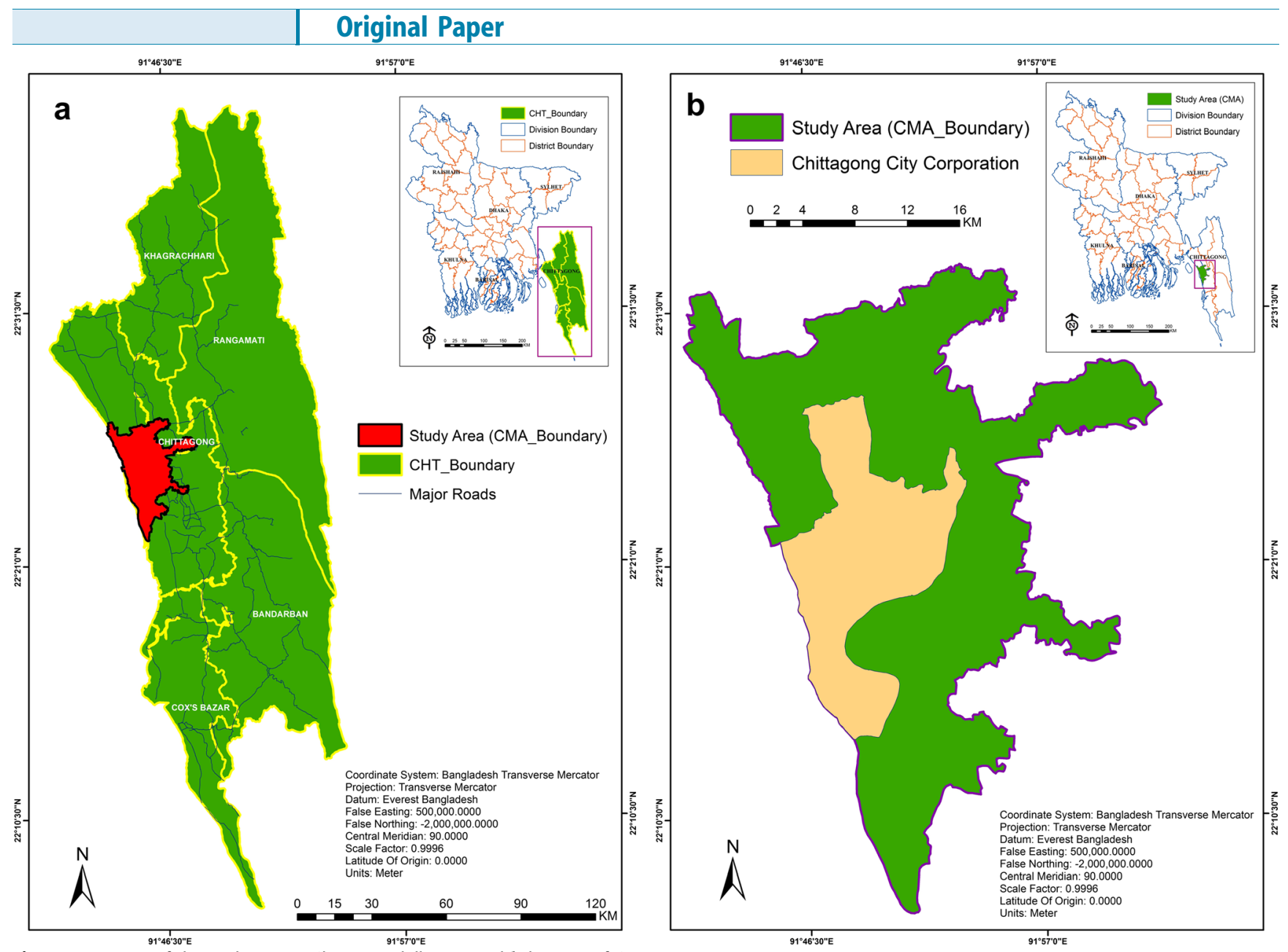

Fig. 1 a Location of the study area in Chittagong hill tracts and $\mathbf{b}$ location of CMA

Moreover, it incorporates the causes of landslides (instability factors) and probabilistic methods (Bai et al. 2010).
There are mainly four methods available to map landslide susceptibility, namely landslide inventory based probabilistic, deterministic,

Table 1 Major landslide events in CMA in recent years*

\begin{tabular}{|c|c|c|c|}
\hline Date & Location & $\begin{array}{l}\text { Rainfall sequence (cumulated } \\
\text { rainfall) }\end{array}$ & Consequences \\
\hline 13 August 1999 & Gopaipur, Kotwali Thana, Chittagong & $\begin{array}{l}435 \mathrm{~mm}-12 \text { days } \\
2-13 \text { Aug } 1999\end{array}$ & 10 people killed \\
\hline 24 June 2000 & Chittagong University Campus & $\begin{array}{l}108 \mathrm{~mm}-8 \text { days } \\
17-24 \text { June } 2000\end{array}$ & 13 people killed and 20 injured \\
\hline 29 June 2003 & Patiya, Chittagong & $\begin{array}{l}658 \mathrm{~mm}-10 \text { days } \\
20-29 \text { June } 2003\end{array}$ & 4 people killed \\
\hline 3 August 2005 & $\begin{array}{l}\text { Nizam Road Housing Society, Panchlaish } \\
\text { area }\end{array}$ & $\begin{array}{l}25 \mathrm{~mm}-2 \text { days } \\
2-3 \text { August } 2005\end{array}$ & 2 people killed and 12 injured \\
\hline 11 June 2007 & Matijharna Colony,Lalkhan Bazar & $\begin{array}{l}610 \mathrm{~mm}-8 \text { days } \\
4-11 \text { June } 2007\end{array}$ & 128 people killed and 100 injured \\
\hline 10 September 2007 & Nabi Nagar, Chittagong & $\begin{array}{l}452 \mathrm{~mm}-7 \text { days } \\
4-10 \text { Sept } 2007\end{array}$ & 2 people killed \\
\hline 18 August 2008 & Matijharna, Chittagong & $\begin{array}{l}454 \mathrm{~mm}-11 \text { days } \\
8-18 \text { August } 2008\end{array}$ & 11 people killed and 25 injured \\
\hline 26 June 2012 & Lebubagan area and Foys lake surroundings & $\begin{array}{l}889 \mathrm{~mm}-8 \text { days } \\
19-26 \text { June } 2012\end{array}$ & 90 people killed and 150 injured \\
\hline
\end{tabular}

*Source: Comprehensive Disaster Management Programme-II (CDMP-II), Ministry of Food and Disaster Management, Bangladesh; and Field Survey, (September 2013). 
Fig. 2 Annual rainfall pattern of

Chittagong City from 1960 to 2010.

(Data source: Bangladesh

Meteorological Department, 2013)

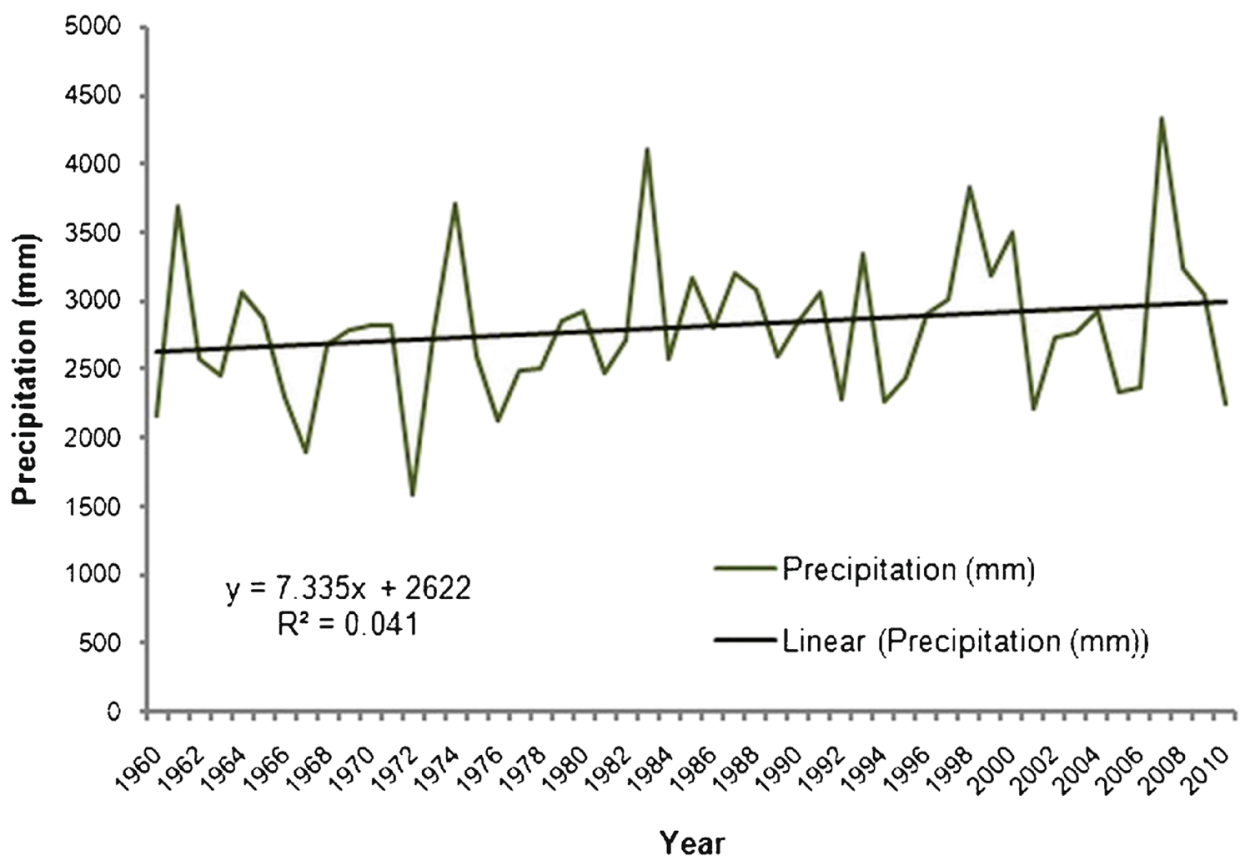

heuristic, and statistical techniques (Guzzetti et al. 1999). Landslide inventory-based probabilistic techniques involve the inventory of landslides, construction of databases, geomorphological analysis, and producing the susceptibility maps based on the collected data (Duman et al. 2005). Deterministic techniques (quantitative methods) involve the estimation of quantitative values of stability variables and require the creation of a map that displays the spatial distribution of input data (Godt et al. 2008; Isik Yilmaz 2009).
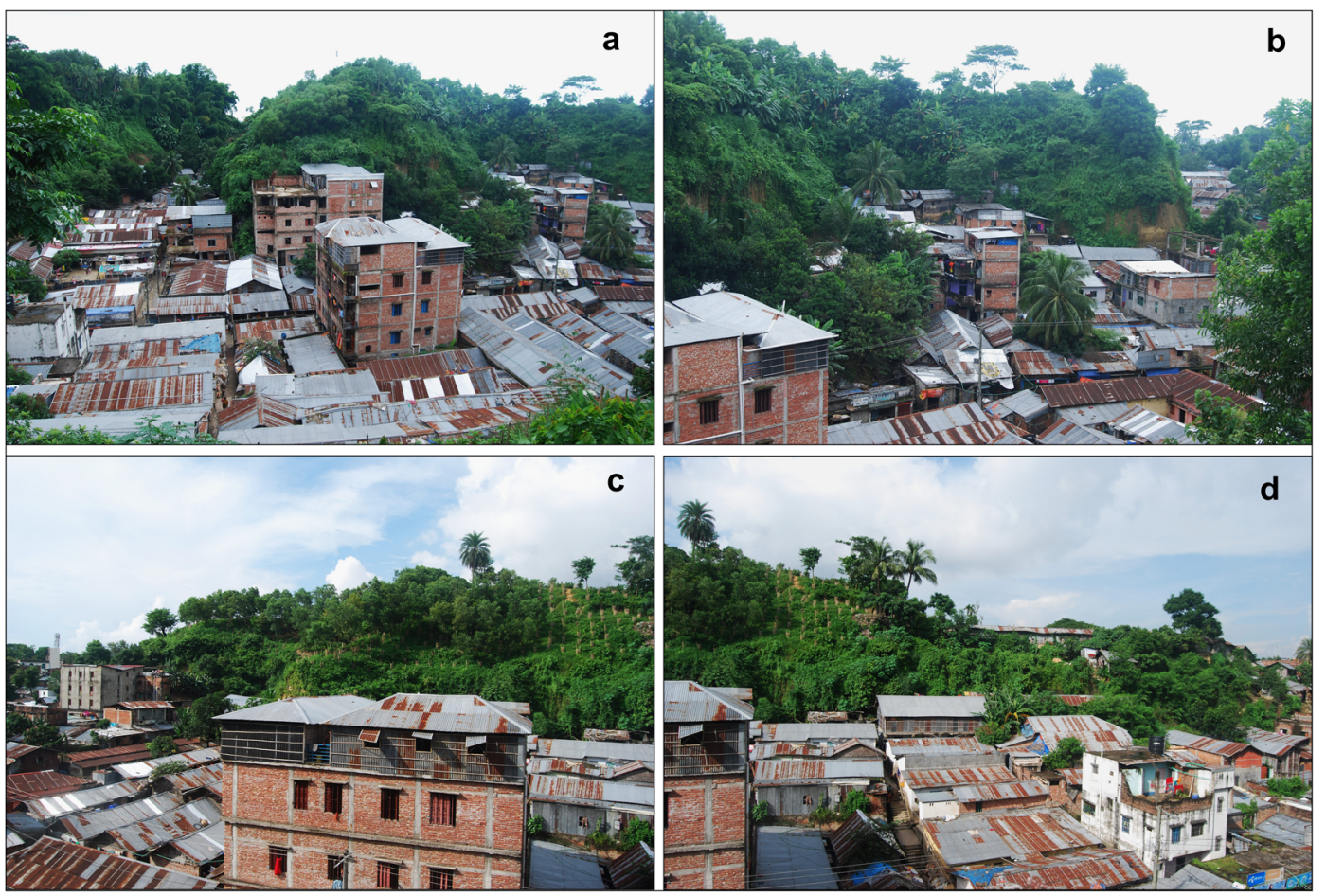

Fig. 3 Landslide vulnerable areas in Matijharna, CMA. (Source: Field visit, September 2013) 
reported (Park et al. 2013). These methods use sample data based on the relationship between the dependent variable (the presence or absence of landslides), and the independent variables (landslides triggering/causative factors). Through these statistical techniques, quantitative predictions are possible to make for areas where there is no landslides and with similar conditions (Isik Yilmaz 2009).

Within these techniques, the probabilistic and statistical methods have been commonly used in recent years. These methods have become more popular, assisted by GIS and RS techniques (Lee and Sambath 2006). The probabilistic (nondeterministic) models like frequency ratio, bivariate analysis, multivariate analysis, and Poisson probability model (Bui et al. 2013) are more frequently used to determine the landslide susceptibility zones (Zêzere et al. 2008). Among the widely used statistical method is the logistic regression (Isik Yilmaz 2009). Many researchers have also used different techniques such as heuristic approach (Karsli et al. 2009) and deterministic models (Avtar et al. 2011).

Moreover, GIS-based Multi Criteria Decision Analysis (GISMCDA) provides powerful techniques for the analysis and prediction of landslide hazards. GIS-MCDA belongs to heuristic analysis. These include the Analytic Hierarchy Process (AHP), the Weighted Linear Combination (WLC), the Ordered Weighted Average (OWA), etc. (Feizizadeh and Blaschke 2013).
Most recently, new non-parametric techniques like cellular automata, fuzzy-logic, artificial neural networks (Poudyal et al. 2010), support vector machines, and neuro-fuzzy models have also been used for landslide susceptibility modelling (Park et al. 2013).

The primary objective of this paper is to apply GIS-MCDA techniques for the Landslide Susceptibility Mapping (LSM) in CMA, Bangladesh. The reason behind choosing GIS-MCDA is that it is being widely used in LSM in recent years (Feizizadeh and Blaschke 2013; Park et al. 2013; Ahammad 2009; Kayastha et al. 2012).

\section{Study area profile}

Chittagong is the second-largest and main seaport of Bangladesh. The city is comprised of small hills and narrow valleys, bounded by the Karnaphuli River to the south-east, the Bay of Bengal to the west, and Halda River to the north-east (Fig. $1 b)$. The city has a population of about 5 million and is constantly growing (Community Report, Chittagong District 2012). The study area, CMA, is situated within $22^{\circ} 14^{\prime}$ and $22^{\circ} 24^{\prime} 30^{\prime \prime}$ north latitude and between $91^{\circ} 46^{\prime}$ and $91^{\circ} 53^{\prime}$ east longitude (Fig. 1b). The total area of CMA is approximately $775 \mathrm{~km}^{2}$ (using Bangladesh Transverse Mercator projection). CMA is also known as 'Chittagong Metropolitan Master Plan (CMMP) Surveyed Area'.

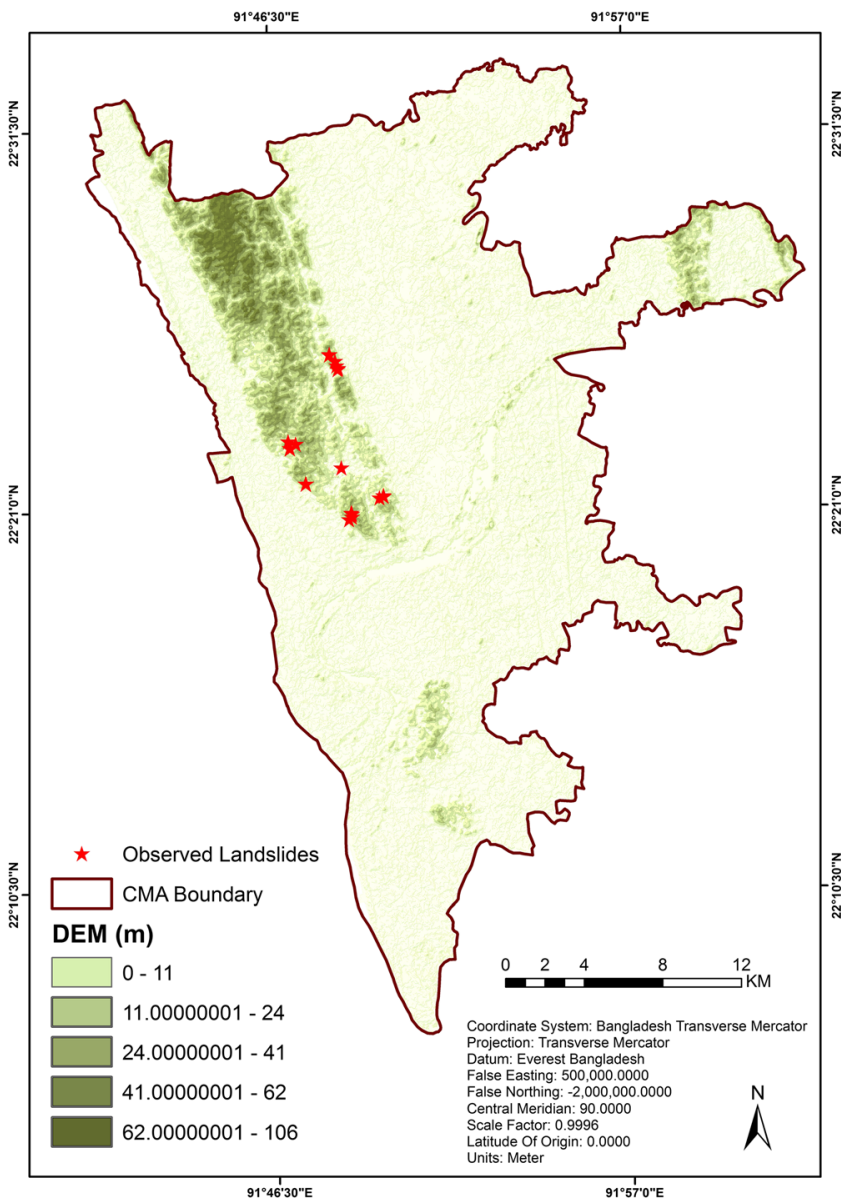

Fig. 4 Landslide inventory map

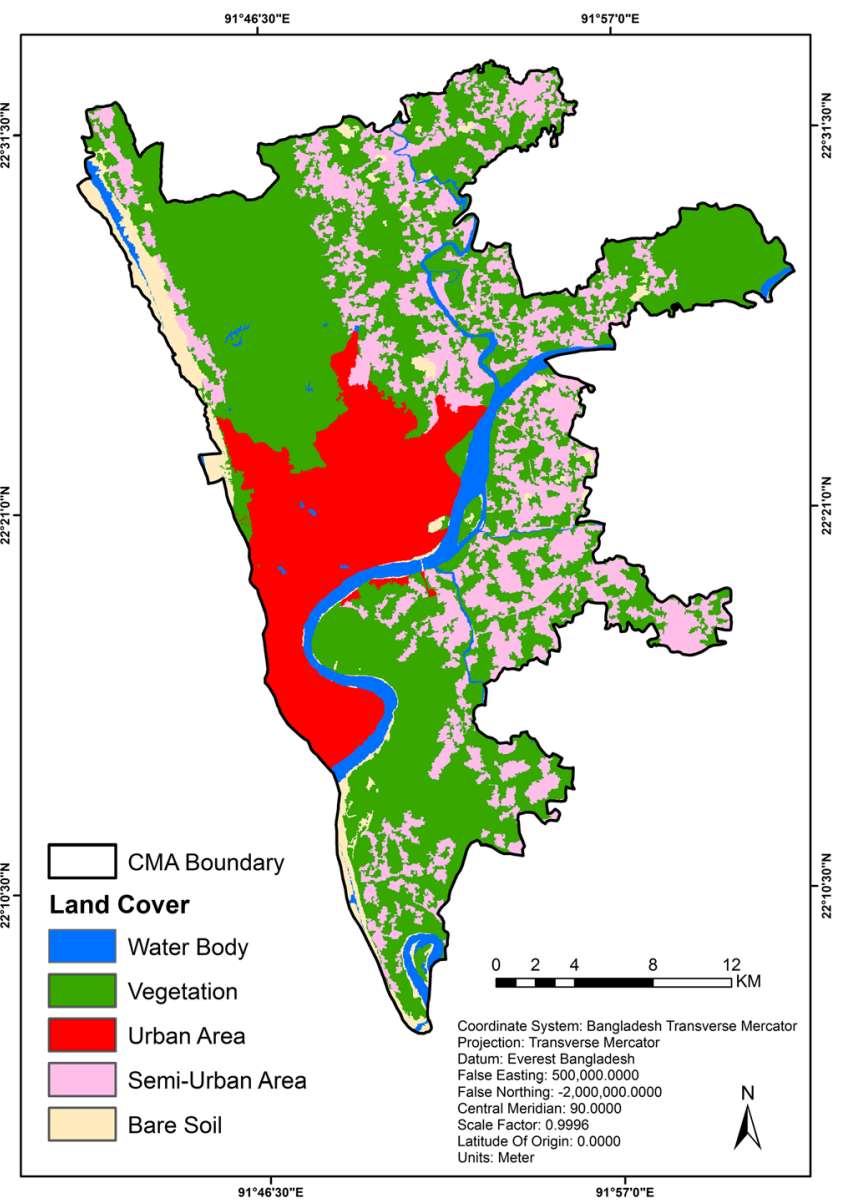

Fig. 5 Land cover map 
CMA is a part of the Chittagong Hill Tracts (CHT) region (Fig. 1a). Therefore, it is important to know about the characteristics of CHT to understand the causes and geological reasons of landslides in CMA. CHT is originated as a result of the collision between India and Asia. Later, India broke apart from Australia and started to drift north-easterly. That is the time when the history began for CHT (Chowdhury 2012). The weather of CHT (Fig. 1a) is characterised by tropical monsoon climate with mean annual rainfall nearly $2,540 \mathrm{~mm}$ in the north-east and 2,540 to $3,810 \mathrm{~mm}$ in the south-west. The monsoon season is from June to October, which is warm, cloudy, and wet (Chowdhury 2012). Moreover, due to climate change, CMA is experiencing higher intensity of rainfall in recent years which is making the landslide situation worse (Mangiza 2011). A gradual upward shift in precipitation is noted in the last five decades (1960-2010), with an abrupt fluctuation in the mean annual precipitation levels (Fig. 2).

The hilly soils in CHT are mainly yellowish brown to reddish brown loams which grade into broken shale or sandstone as well as mottled sand at a variable depth. According to the physiography of Bangladesh, CHT falls under the Northern and Eastern Hill unit and the High Hill or Mountain Ranges sub-unit. At present, all the mountain ranges of $\mathrm{CHT}$ are almost hogback ridges. They rise steeply, thus, looking far more impressive than their height would imply. Most of the ranges have scarps in the west, with cliffs and waterfalls. The region is characterised by a huge network of trellis and dendritic drainage consisting of some major rivers draining into the Bay of Bengal (Chowdhury 2012).

In general, the geological structures and soils are weak in CMA. Moreover, the hills have steep slopes that are vulnerable to landslides (Khan et al. 2012). The general soil type in CMA is termed as 'brown hill soil'. The soils consist of hard red clay with a mixture of fine sand of the same colour and nodules containing a large percentage of sesquioxides. The soils are moderately to strongly acidic. Major limitations include very steep slopes, heavy monsoon rainfall, erodibility of most soils, difficulty of making terrace, generally low soil fertility, and rapid permeability. The soils are highly leached and have a low natural fertility. Hills are mainly under natural and plantation forests. Shifting cultivation is practiced in some places (Islam 2012). The landslides in CMA were classified as 'earth slides' since those consist of $80 \%$ sand and finer particles. These landslides were shallow in nature and occurred just during/after the rainfall. It has been stated that the rainfall intensity and duration play very important roles in producing these shallow landslides in CMA (Ahammad 2009). Figure 3 depicts how people of Matijharna, an informal residential area within CMA, are living at the risks of landslide hazards. On 11 June 2007, about 128 people died and 100 others were injured in this area due to landslides triggered by heavy rainfall for continuous 8 days (CDMP-II, Ministry of Food and Disaster Management, Bangladesh 2012).

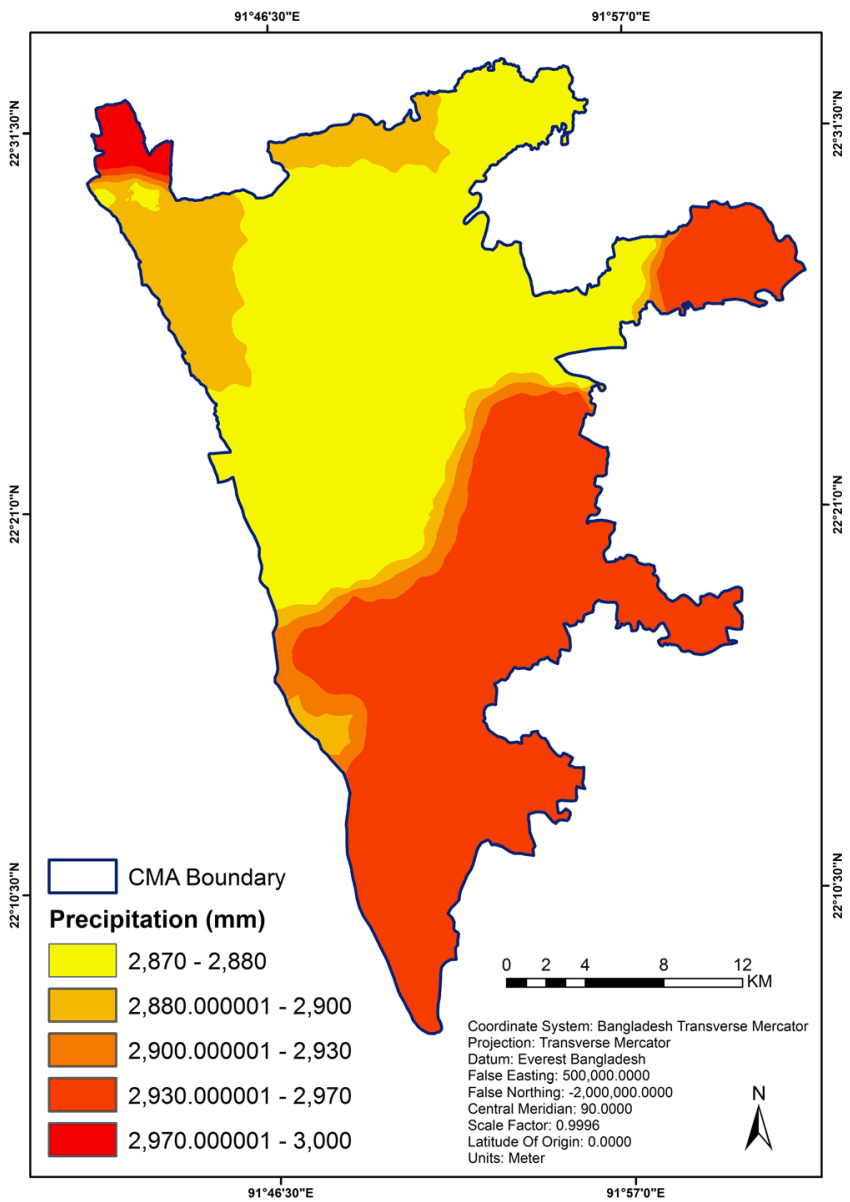

Fig. 6 Precipitation map

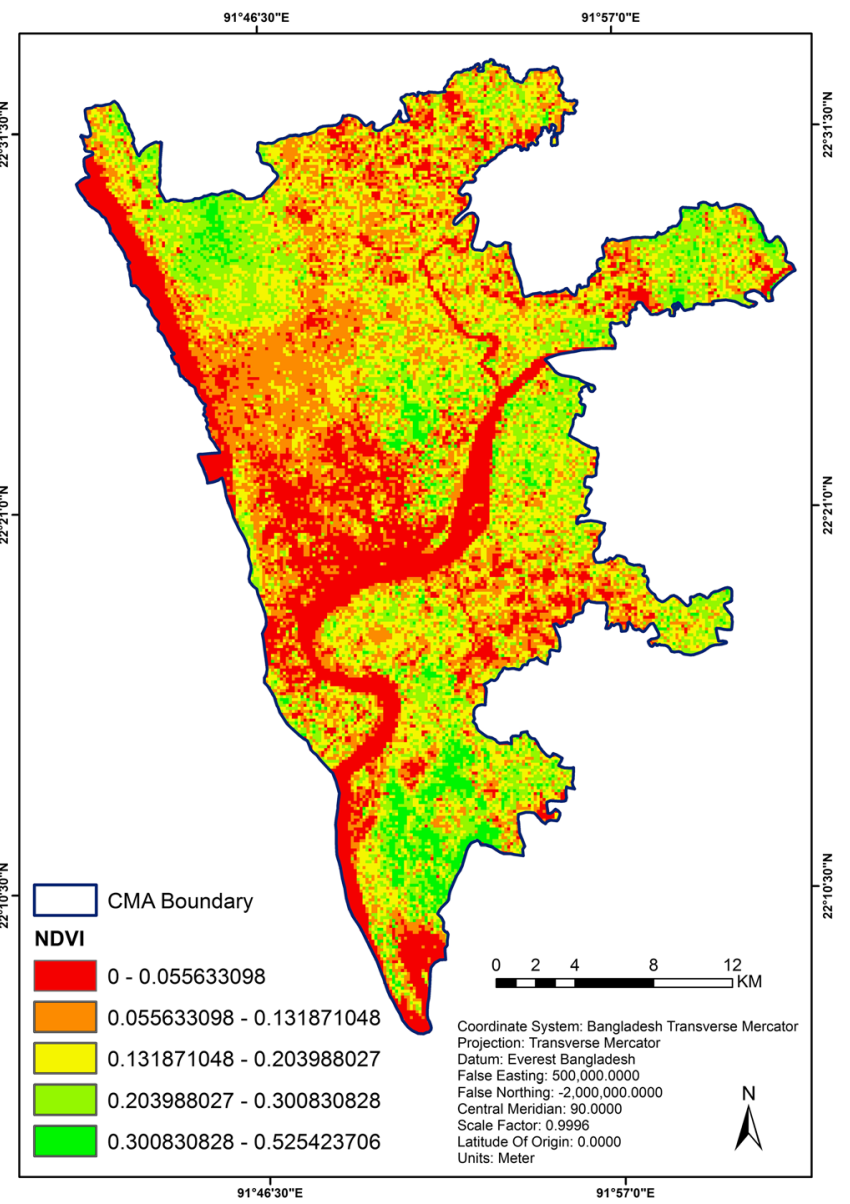

Fig. 7 NDVI map 


\section{Data collection}

To produce landslide susceptible maps, it is important to know the causative factors and to prepare the necessary thematic layers. For this research purpose, nine different GIS layers have been produced for LSM. All the raster images $(30 \mathrm{~m} \times 30 \mathrm{~m})$ were projected to 'Bangladesh Transverse Mercator (BTM)' using 'Everest Bangladesh' datum. Moreover, where necessary, the maps were classified using Natural Breaks (Jenks) method with 5 classes. Natural breaks classes are based on natural groupings inherent in the data. It identifies break points by picking the class breaks that best group similar values and maximize the differences between classes. The features are then divided into classes whose boundaries are set where there are relatively big jumps in the data values. Natural breaks are data-specific classifications; this is why this method is chosen (ArcGIS ${ }^{\circledR}$ 10 Help 2012). The details of the data collection procedure and ways of preparing the thematic layers are described as follows:

\section{Landslide inventory map}

A total of 20 landslide locations were identified in CMA through field visits. The latitude and longitude values were collected using a GPS device. The Digital Elevation Model (DEM) image (acquired on 29 November 2013) was collected from the Advanced Space-borne Thermal Emission and

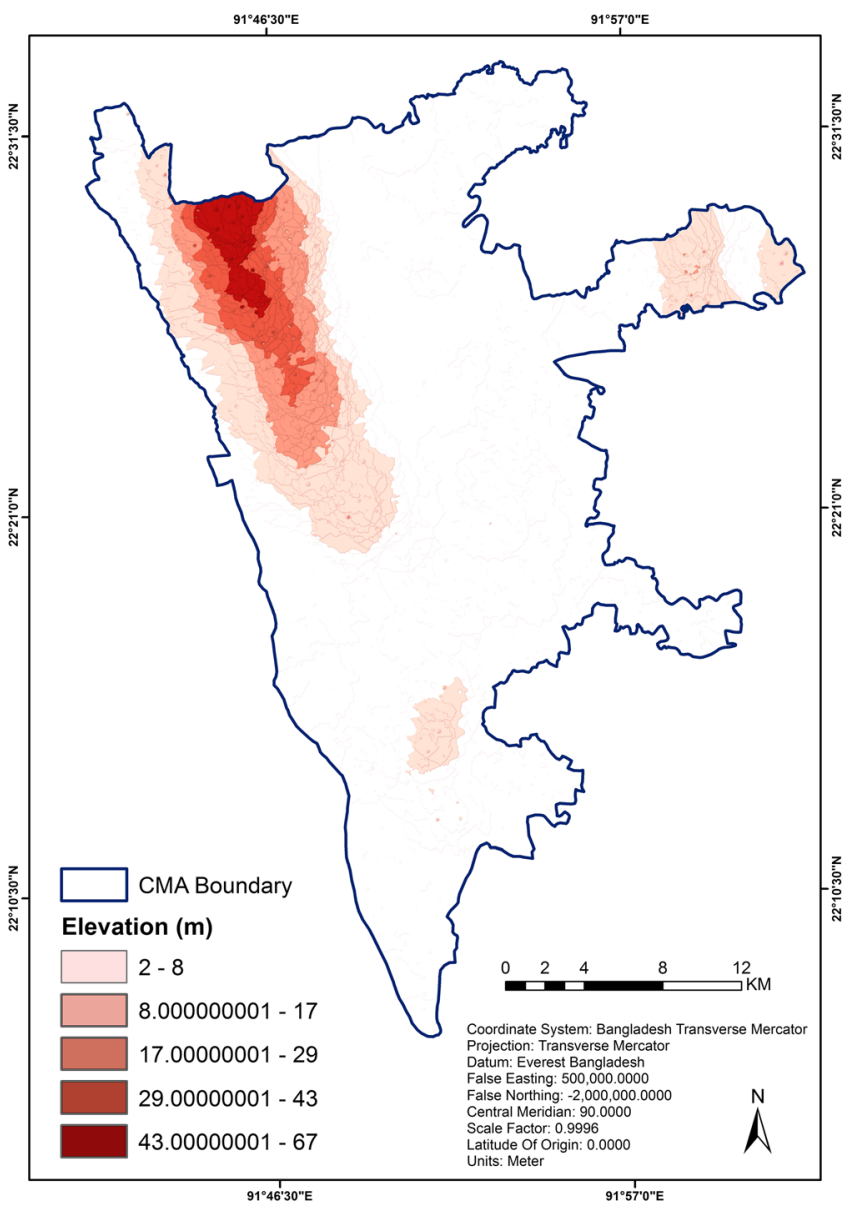

Fig. 8 Elevation map
Reflection Radiometer-Global Digital Elevation Model webportal (Tachikawa et al. 2011). The 20 observed landslide locations in CMA are represented in Fig. 4.

\section{Land cover map}

Landsat Thematic Mapper (TM) satellite images were used for the land cover mapping (2010) of CMA. The images were acquired from the Global Visualization Viewer of the United States Geological Survey (USGS). The land cover classification methodology was based on the Object Based Image Analysis (Uddin 2013; Ahmed and Rubel 2013). Finally, five broad land cover types (urban area, semi-urban area, water body, vegetation, and bare soil) were identified (Fig. 5).

Now, it is important to perform accuracy assessment. As it was not possible to ground truth the classified image, therefore, a total of 300 reference pixels were generated using stratified random sampling method. Then, the reference pixels were compared with the base map (2010) collected from the Chittagong Development Authority (CDA). The producer's, users, and overall accuracy were found as $84.88,87.67$, and $86.80 \%$, respectively (Ahmed and Ahmed 2012).

\section{Precipitation map}

The daily observed precipitation data (1960-2010) were collected from the Bangladesh Meteorological Department (BMD). Moreover, the average annual precipitation map (Fig. 6) was extracted

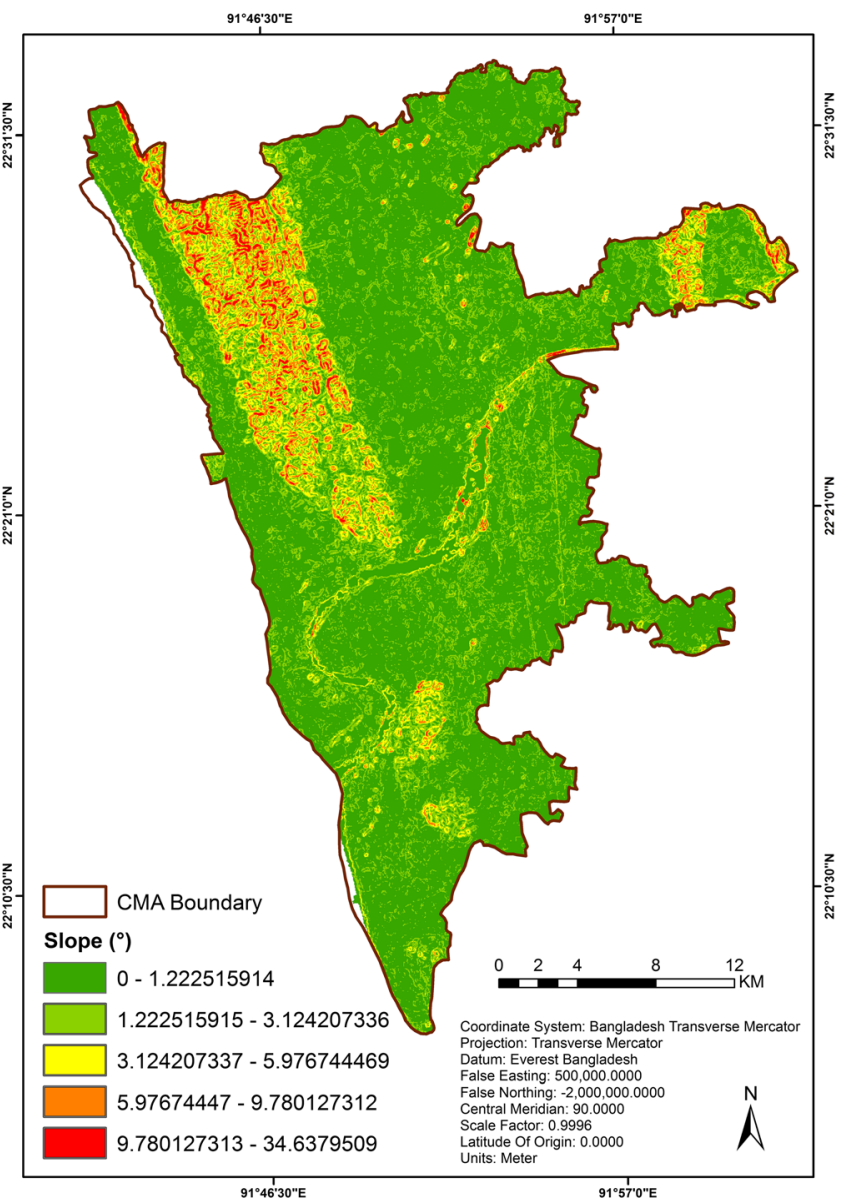

Fig. 9 Slope map 
from the maps collected from the Geological Survey of Bangladesh (GSB) and the USGS website (Persits et al. 2001).

\section{Normalized difference vegetation index map}

The Normalized Difference Vegetation Index (NDVI) is a standardized index that allows generating an image displaying greenness (relative biomass). The NDVI equation is as follows (ArcGIS ${ }^{\circledR}$ 10 Help 2012):

$\mathrm{NDVI}=((I R-R) /(I R+R))$

where IR=pixel values from the infrared band (band 4) and $\mathrm{R}=$ pixel values from the red band (band 3 ). This index output values between -1.0 and 1.0, mostly representing greenness, where any negative values are mainly generated from clouds, water, and snow, and values near zero are mainly generated from rock and bare soil. Very low values of NDVI ( 0.1 and below) correspond to barren areas of rock or sand. Moderate values (0.2 to 0.3 ) represent shrub and grassland, while high values (o.6 to 0.8 ) indicate temperate and tropical rainforests (Ahmed et al. 2013a; ArcGIS ${ }^{\circledR} 10$ Help 2012). In this research, the Landsat 4-5 TM images from the same season (dry and summer) were acquired from the official website of the USGS. Finally, the NDVI map (Fig. 7) of CMA was prepared by analysing band 3 and band 4 .

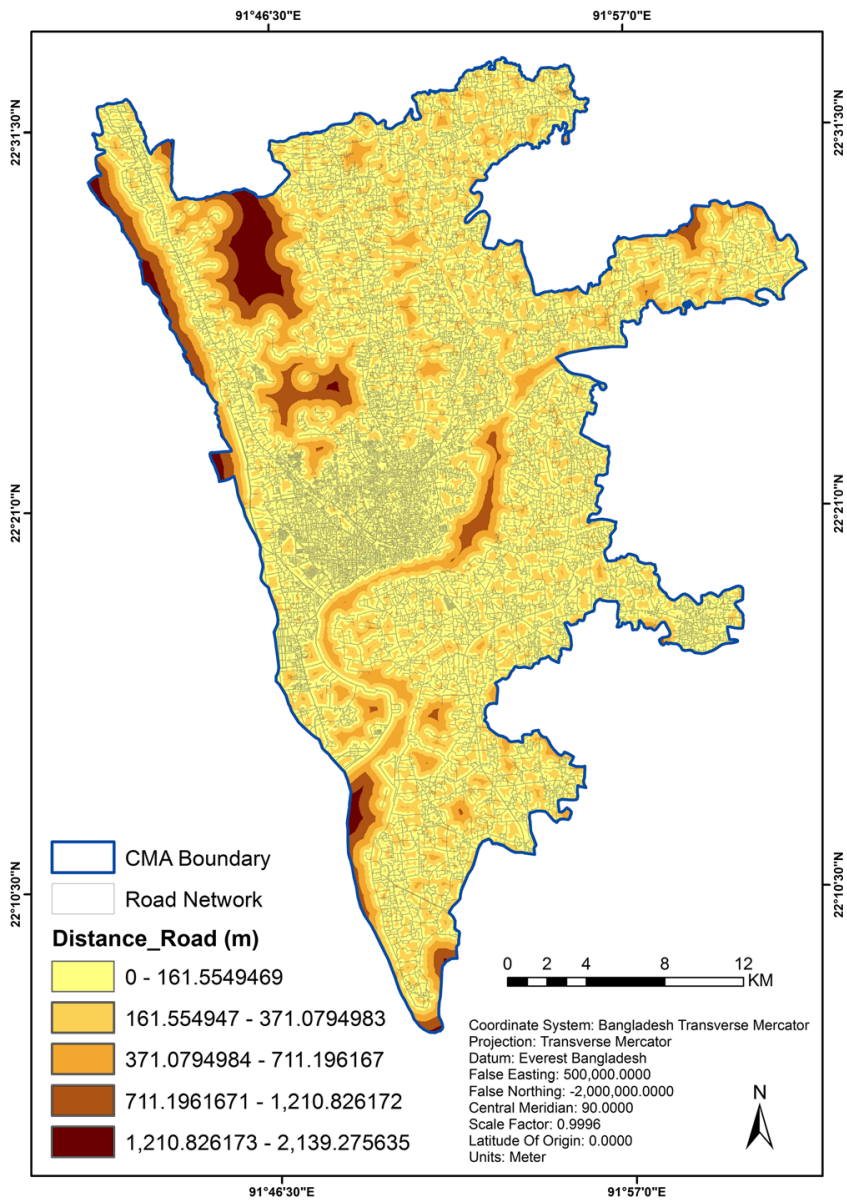

Fig. 10 Distance to road map

\section{Elevation and slope map}

Elevation and slope maps were produced from DEM layer. The maps were then classified using Natural Breaks (Jenks) method (ArcGIS ${ }^{\circledR} 10$ Help 2012) with 5 classes (Figs. 8 and 9).

\section{Other layers}

The road network, drainage network, and water body layers were collected from CDA. The distance images from all these layers were prepared using 'Euclidean Distance' technique (ArcGIS ${ }^{\circledR} 10$ Help 2012), which gives the distance from each cell in the raster to the closest source (Figs. 10, 11, and 12). The Euclidean distance tools give information according to Euclidean or straight-line distance. Euclidean distance is calculated from the centre of the source cell to the centre of each of the surrounding cells. True Euclidean distance is calculated in each of the distance tools (ArcGIS ${ }^{\circledR} 10$ Help 2012). The soil permeability map (Fig. 13) was collected from GSB and USGS (Persits et al. 2001).

\section{Landslide susceptibility-mapping methods}

In this research, three MCDA methods were used for LSM. These were AHP, WLC, and OWA. MCDA is a GIS-based overlaying method used to combine a set of criteria to achieve a single composite basis for a decision according to a specific objective (Eastman 2012). MCDA technique is useful for overlaying large data/maps and easy to understand/implement. The expert's or

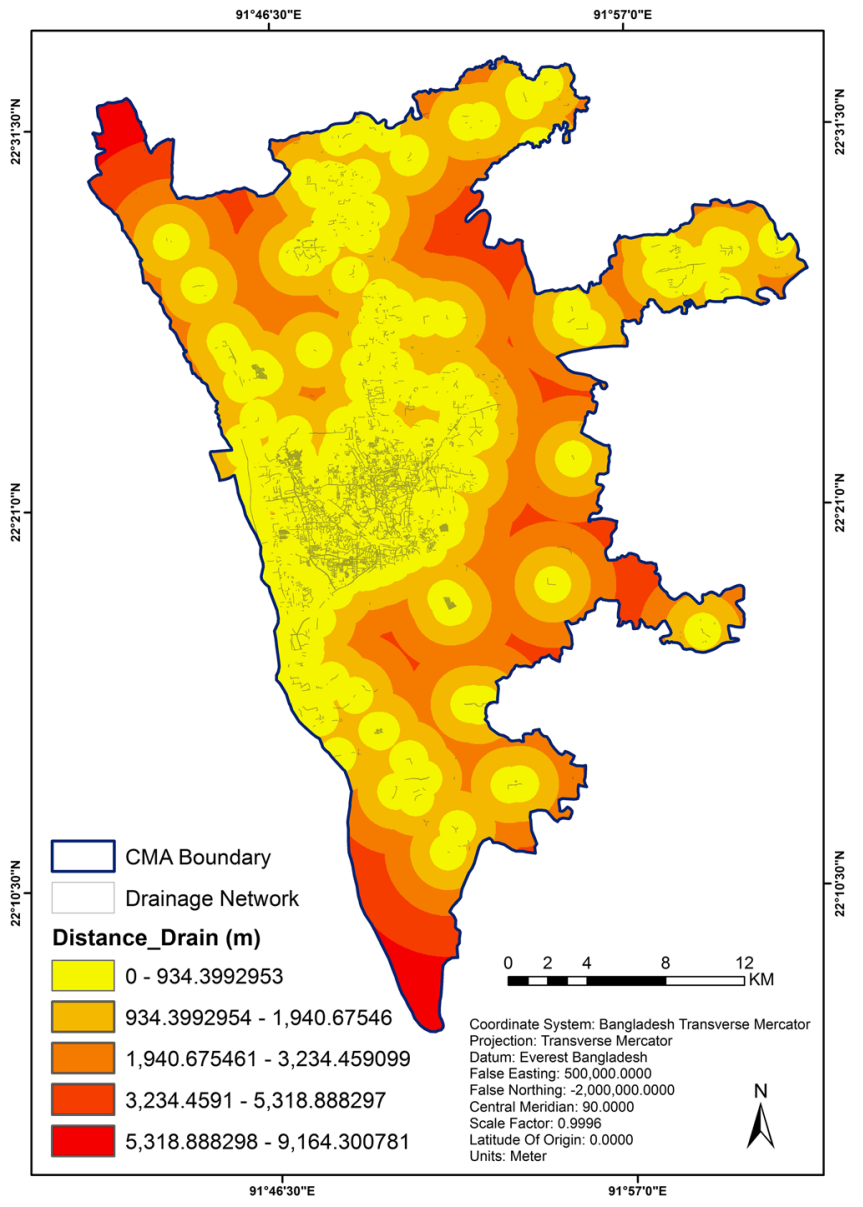

Fig. 11 Distance to drain map 
decision maker's preferences get importance in these methods. Therefore, the main drawback of MCDA is only failing to choose appropriate assumptions/criteria for suitability analysis (Malczewski 2004). In this study, IDRISI ${ }^{\circledR}$ Selva and ArcGIS ${ }^{\circledR}$ 10.2 software were used for LSM in CMA.

\section{Analytical hierarchy process}

The AHP method is used to derive the weights associated with suitability/attribute map layers (Saaty 1977). Later the weights can be combined with the attribute map layers (Malczewski 2004). AHP can deal with complex decision making and also useful for checking the consistency of the evaluation measures as suggested by the decision makers. The input of this method can be price, weight etc. AHP builds a hierarchy of decision criteria through pairwise comparison of each possible criterion pair (Poudyal et al. 2010; Feizizadeh and Blaschke 2013).

The weights can be derived by taking the principal eigenvector of a square reciprocal matrix of pairwise comparisons between the criteria. It is also necessary that the weights sum to one. The comparisons concern the relative importance of the two criteria involved in determining suitability for the stated objective. Ratings are provided on a 9-point continuous scale: $(1 / 9,1 / 8,1 / 7,1 / 6,1 / 5,1 / 4,1 / 3,1 / 2,1$, $2,3,4,5,6,7,8,9)$. The values range from $1 / 9$ representing the least important, to 1 for equal importance and to 9 for the most important, covering all the values in the set (Eastman 2012). It is also possible to determine the degree of consistency that has been used in developing the ratings (Eastman 2012). It is a procedure by which an index of consistency, known as a consistency ratio (CR), can be produced. The CR indicates the probability that the matrix ratings were randomly generated. It is stated that matrices with CR ratings greater than 0.10 should be re-evaluated (Saaty 1977).

\section{Weighted linear combination}

In WLC or simple additive weighting method, the decision maker directly assigns the weights of relative importance to each attribute map layer. A total score is then obtained for each alternative by multiplying the importance weight assigned for each attribute by the scaled value given to the alternative on that attribute and summing the products over all attributes. When the overall scores are calculated for all of the alternatives, the alternative with the highest overall score is chosen (Malczewski 2004). Due to the criterion weights being summed to one, the final scores of the combined solution are expressed on the same scale (Feizizadeh and Blaschke 2013). In this case, the higher the factor weight the more influence that factor has on the final suitability map (Saaty 1977).

\section{Ordered weighted averaging}

The OWA method was introduced by Yager (1988). It involves both criterion importance weights and order weights. An importance

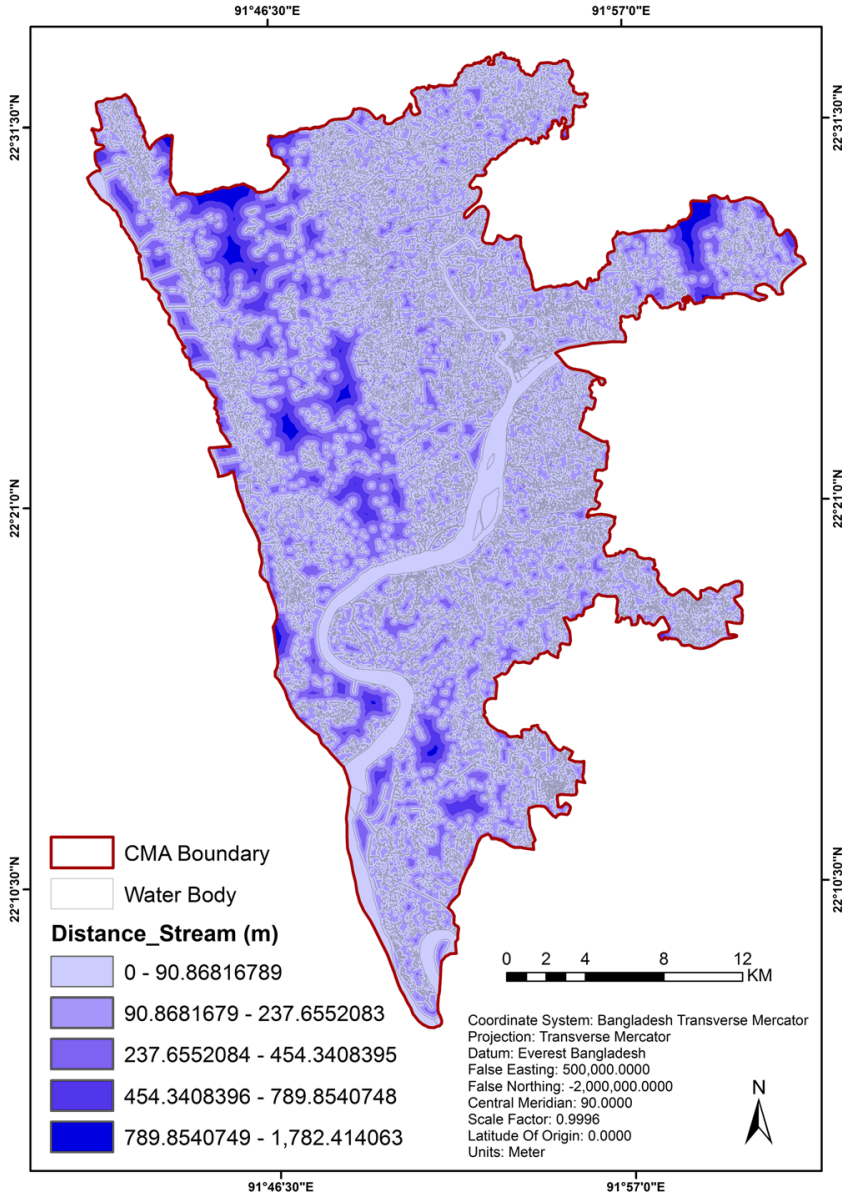

Fig. 12 Distance to stream map

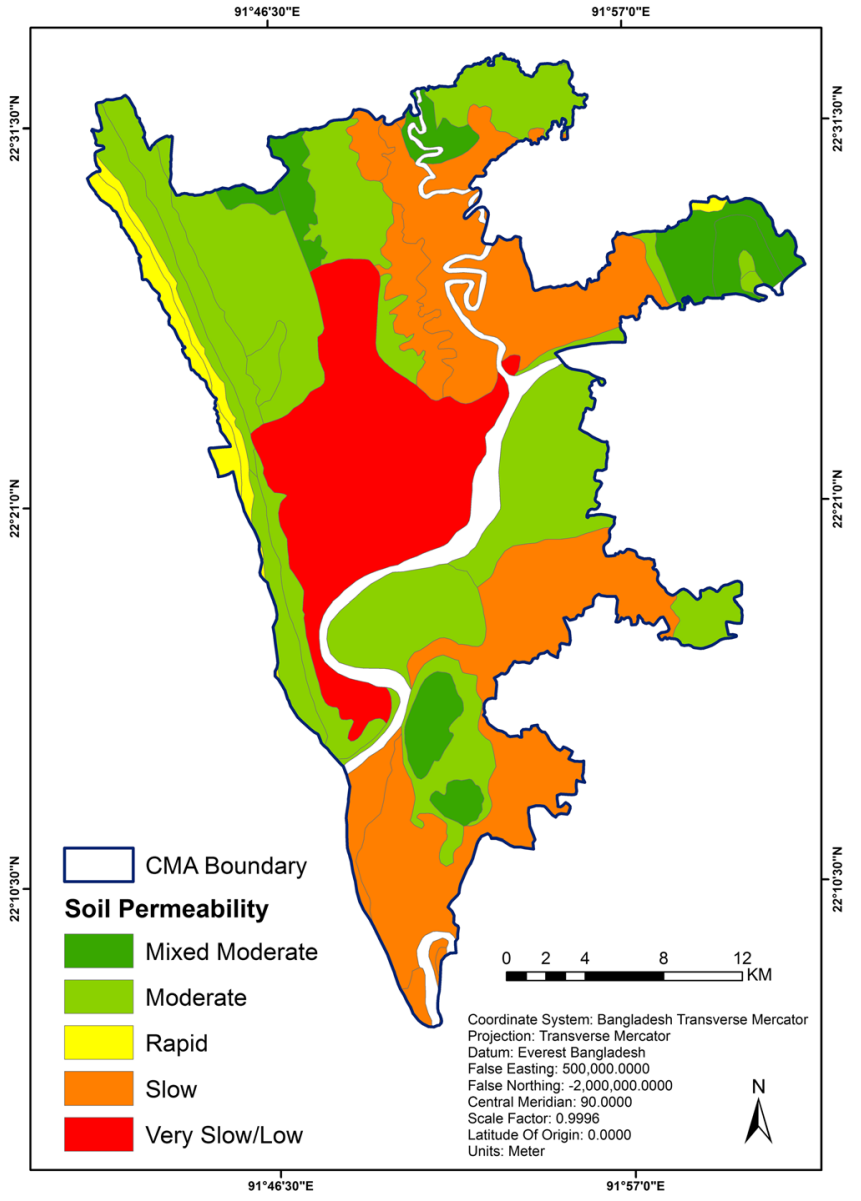

Fig. 13 Soil permeability map 
Table 2 Pairwise comparison matrix, consistency ratio and weights of the sub-criteria of the data layers

Distance to drain $(\mathrm{m})$

(1) $0-934.3992953$
(2) $934.3992954-1,940.67546$
(3) $1,940.675461-3,234.459099$
(4) $3,234.4591-5,318.888297$
(5) $5,318.888298-9,164.300781$

\section{1}

0.0448

$\begin{array}{lll}2 & 0.0699\end{array}$

Consistency ratio: 0.04

Elevation $(\mathrm{m})$
(1) $2-8$
(2) $8.000000001-17$
(3) $17.00000001-29$
(4) $29.00000001-43$
(5) $43.00000001-67$

3
6
7

2

43

65

1
3
5

0.1098 0.2408

0.5346 Consistency ratio: 0.03 Land cover (1)Water body

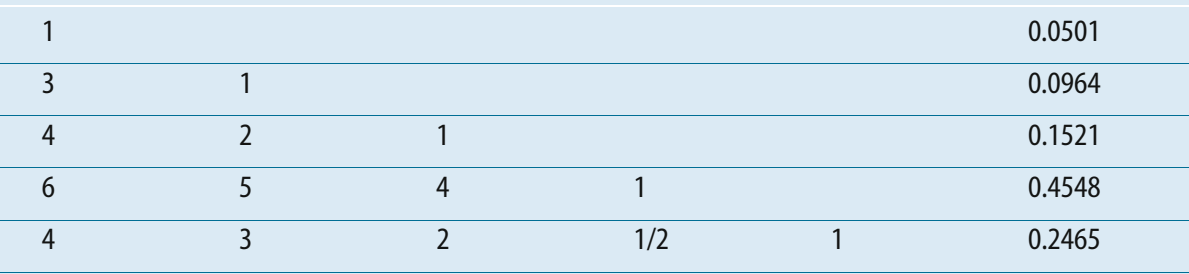

(1)Water body
(2) Vegetation
(3) Urban area
(4) Semi-urban area
(5) Bare soil

$\begin{array}{lll}1 & 1 & 0.1196\end{array}$

$\begin{array}{llll}7 & 6 & 1 & 0.5019\end{array}$

$\begin{array}{lllll}5 & 4 & 1 / 3 & 1 & 0.2537\end{array}$

Consistency ratio: 0.08

NDVI

\begin{tabular}{|c|c|c|c|c|c|}
\hline (1) $0-0.055633098$ & 1 & & & & 0.4380 \\
\hline (2) $0.05563098-0.131871048$ & $1 / 2$ & 1 & & & 0.2913 \\
\hline (3) $0.131871048-0.203988027$ & $1 / 4$ & $1 / 3$ & 1 & & 0.1544 \\
\hline (4) $0.203988027-0.300830828$ & $1 / 5$ & $1 / 4$ & $1 / 3$ & 1 & 0.0881 \\
\hline (5) $0.300830828-0.525423706$ & $1 / 9$ & $1 / 8$ & $1 / 7$ & $1 / 6$ & 0.0282 \\
\hline
\end{tabular}

\section{Consistency ratio: 0.07}

Precipitation $(\mathrm{mm})$

\begin{tabular}{|c|c|c|c|c|c|}
\hline (1) $2,870-2,880$ & 1 & & & & 0.0618 \\
\hline (2) $2,880.000001-2,900$ & 2 & 1 & & & 0.0973 \\
\hline (3) $2,900.000001-2,930$ & 3 & 2 & 1 & & 0.1599 \\
\hline (4) $2,930.000001-2,970$ & 4 & 3 & 2 & 1 & 0.2625 \\
\hline (5) $2,970.000001-3,000$ & 5 & 4 & 3 & 2 & 0.4185 \\
\hline
\end{tabular}

Consistency ratio: 0.02

Distance to road $(\mathrm{m})$

\begin{tabular}{|c|c|c|c|c|c|}
\hline (1) $0-161.5549469$ & 1 & & & & 0.4185 \\
\hline (2) $161.554947-371.0794983$ & $1 / 2$ & 1 & & & 0.2625 \\
\hline (3) $371.0794984-711.196167$ & $1 / 3$ & $1 / 2$ & 1 & & 0.1599 \\
\hline (4) $711.1961671-1,210.826172$ & $1 / 4$ & $1 / 3$ & $1 / 2$ & 1 & 0.0973 \\
\hline (5) $1,210.826173-2,139.275635$ & $1 / 5$ & $1 / 4$ & $1 / 3$ & $1 / 2$ & 0.0618 \\
\hline
\end{tabular}

\section{Consistency ratio:0.02}

\section{Slope $\left({ }^{\circ}\right)$}
(1) $0-1.222515914$ 


\begin{tabular}{|c|c|c|c|c|c|c|}
\hline Factors & (1) & (2) & (3) & (4) & (5) & Eigen values \\
\hline (3) $3.124207337-5.976744469$ & 3 & 4 & 1 & & & 0.1565 \\
\hline (4) $5.97674447-9.780127312$ & 7 & 6 & 5 & 1 & & 0.4869 \\
\hline (5) $9.780127313-34.6379509$ & 4 & 3 & 2 & $1 / 2$ & 1 & 0.2333 \\
\hline \multicolumn{7}{|l|}{ Consistency ratio:0.04 } \\
\hline \multicolumn{7}{|l|}{ Soil permeability } \\
\hline (1)Mixed moderate & 1 & & & & & 0.0385 \\
\hline (2) Moderate & 2 & 1 & & & & 0.0522 \\
\hline (3) Rapid & 3 & 4 & 1 & & & 0.1088 \\
\hline (4) Slow & 5 & 4 & 3 & 1 & & 0.1900 \\
\hline (5) Very slow/ low & 9 & 8 & 7 & 6 & 1 & 0.6105 \\
\hline \multicolumn{7}{|l|}{ Consistency ratio:0.08 } \\
\hline \multicolumn{7}{|l|}{ Distance to stream (m) } \\
\hline$(1) 0-90.86816789$ & 1 & & & & & 0.3999 \\
\hline (2) $90.8681679-237.6552083$ & $1 / 2$ & 1 & & & & 0.2427 \\
\hline (3) $237.6552084-454.3408395$ & $1 / 3$ & $1 / 2$ & 1 & & & 0.1592 \\
\hline (4) $454.3408396-789.8540748$ & $1 / 3$ & $1 / 2$ & $1 / 2$ & 1 & & 0.1200 \\
\hline (5) $789.8540749-1,782.414063$ & $1 / 4$ & $1 / 3$ & $1 / 2$ & $1 / 2$ & 1 & 0.0783 \\
\hline
\end{tabular}

weight is assigned to a given criterion/factor for all locations in a study area to indicate its relative importance according to the decision maker's preferences (Malczewski 2004). Order weights are a set of weights assigned not to the factors themselves but to the rank order position of factor values for a given location/pixel (Eastman 2012). The number of order weights is equal to the number of criteria and must sum to one (Jiang and Eastman 2000).

\section{Results}

Calculating factor weights has a crucial role in the production of landslide susceptibility maps by applying GIS-MCDA methods (Kavzoglu et al. 2013). The calculations of relative weights of the factors and order were based on the expert opinion surveying, analysing the landslide inventory map, and local knowledge obtained from field surveying.

\section{LSM using AHP method}

To apply the AHP method, first it is necessary to construct a pairwise matrix. Then, both the weight values of sub-criteria of the criterions and the datasets/factors were calculated (Tables 2 and 3). In the next step, the CR was calculated in order to determine whether the pairwise comparisons were consistent or not (Saaty 1977). In this research, the resulting CR for all the cases was found less than 0.10 (Tables 2 and 3). It means the relative weights were appropriate and the comparisons were consistent (Saaty 1977; Feizizadeh and Blaschke 2013).

It was found that the highest weight was assigned to soil permeability map. Slope, elevation, land cover, and NDVI factors were also found effective. The other layers (i.e., precipitation, distance to drain, road, and stream) were identified as less important (Table 3).

Table 3 Pairwise comparison matrix, factor weights and consistency ration of the data layers

\begin{tabular}{|c|c|c|c|c|c|c|c|c|c|c|}
\hline Factors & (1) & $(2)$ & (3) & (4) & (5) & (6) & (7) & (8) & (9) & Eigen values \\
\hline (1) Distance to drain & 1 & & & & & & & & & 0.0469 \\
\hline (2) Elevation & 5 & 1 & & & & & & & & 0.1989 \\
\hline (3) Land cover & 3 & $1 / 3$ & 1 & & & & & & & 0.0975 \\
\hline (4) NDVI & 2 & $1 / 4$ & $1 / 2$ & 1 & & & & & & 0.0706 \\
\hline (5) Precipitation & $1 / 3$ & $1 / 7$ & $1 / 4$ & $1 / 3$ & 1 & & & & & 0.0366 \\
\hline (6) Distance to road & $1 / 3$ & $1 / 8$ & $1 / 6$ & $1 / 5$ & $1 / 2$ & 1 & & & & 0.0243 \\
\hline (7) Slope & 5 & 1 & 5 & 4 & 3 & 6 & 1 & & & 0.1989 \\
\hline (8) Soil permeability & 7 & 2 & 5 & 6 & 8 & 9 & 2 & 1 & & 0.3074 \\
\hline (9) Distance to stream & $1 / 2$ & $1 / 7$ & $1 / 6$ & $1 / 5$ & $1 / 4$ & $1 / 3$ & $1 / 7$ & $1 / 8$ & 1 & 0.0190 \\
\hline
\end{tabular}


After applying the AHP generated weights in the data layers, the resulting map was reclassified into three meaningful levels as: low, medium, and high susceptibility zones (Fig. 14). This is helpful for presentation and evaluation purposes. An expert knowledge-based classification was used to define the class intervals. This technique of landslide susceptibility zoning was implemented for the rest two methods (WLC and OWA).

\section{LSM using WLC method}

Based on expert opinion surveying and using local knowledge, three different combinations of factor weights were generated (Table 4). At first, the factor maps multiplied the weights from the pairwise comparison matrix and all the weighted factor maps were then aggregated. Finally, the maps were reclassified to produce the WLC generated landslide susceptibility maps (Fig. 15).

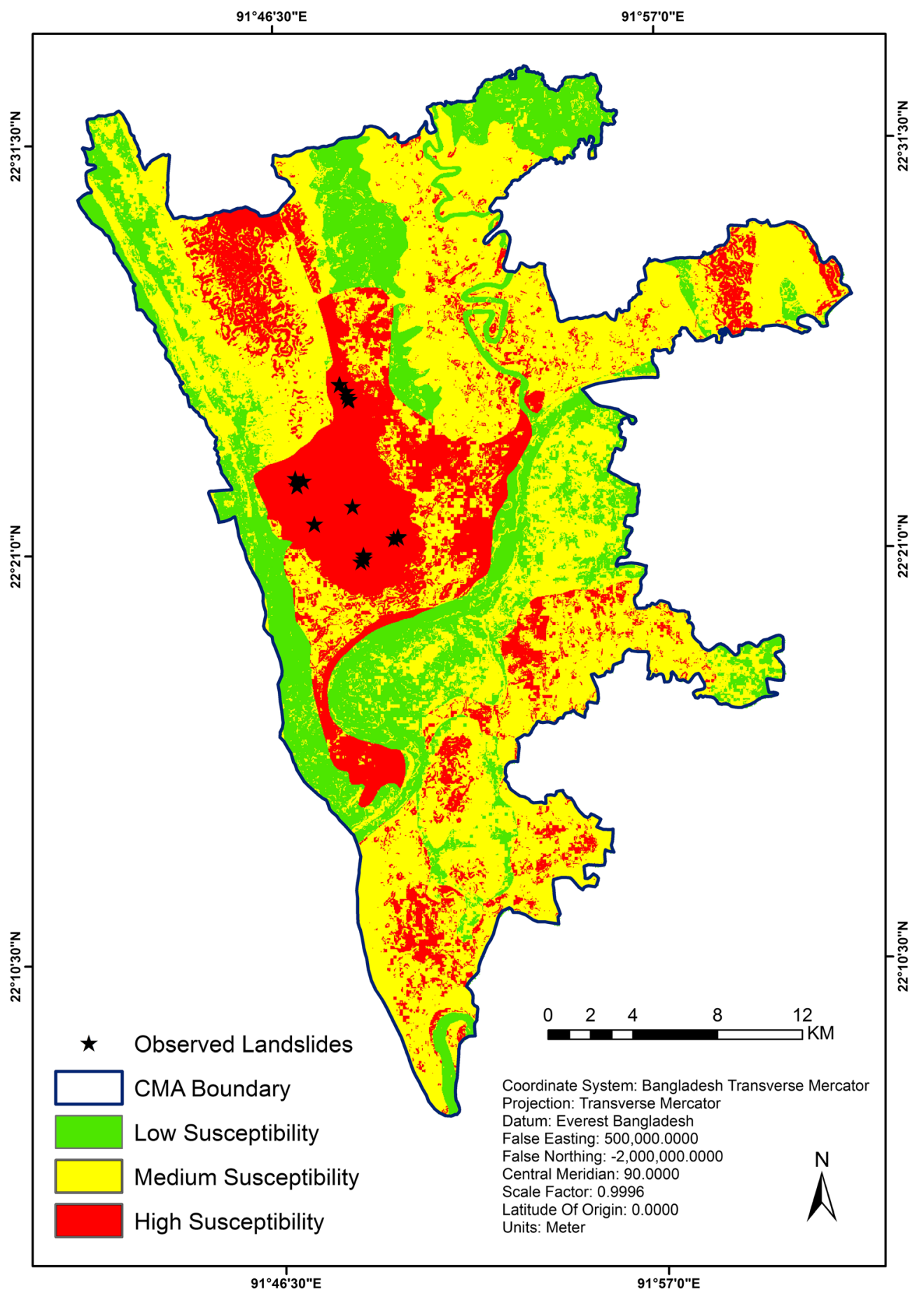

Fig. 14 Landslide susceptibility map derived from AHP method 
Table 4 Factor weights for WLC analysis

\begin{tabular}{|llll}
\hline Factors & Weight_1 & Weight_2 & Weight_3 \\
\hline Distance to drain & 0.05 & 0.10 & 0.10 \\
\hline Elevation & 0.10 & 0.10 & 0.15 \\
\hline Land cover & 0.10 & 0.15 & 0.15 \\
\hline NDVI & 0.10 & 0.10 & 0.10 \\
\hline Precipitation & 0.05 & 0.05 & 0.05 \\
\hline Distance to road & 0.05 & 0.05 & 0.05 \\
\hline Slope & 0.10 & 0.15 & 0.15 \\
\hline Soil permeability & 0.40 & 0.25 & 0.20 \\
\hline Distance to stream & 0.05 & 0.05 & 0.05 \\
\hline Total & 1.00 & 1.00 & 1.00 \\
\hline
\end{tabular}

\section{LSM using OWA method}

OWA method uses order weights in addition to criterion/factor weights. Order weights control the manner in which the weighted factors are aggregated (Eastman and Jiang 1996). In traditional WLC method, criteria weights determine how factors trade-off relative to each other (Jiang and Eastman 2000). Trade-off is the degree to which one factor can compensate for another; how they compensate is governed by a set of 'factor weights'/'trade-off weights'. A factor with a high factor/trade-off weight may compensate for low suitability in other factors that have lower factor/ trade-off weights (Eastman 2012). However, the level of trade-off is not adjustable in WLC. But, in the case of OWA method, the criteria weights can be adjusted according to the level of tradeoff by using the order weights (Jiang and Eastman 2000).

The factor with the lowest suitability score, after factor weights are applied, is given the first order weight. The factor with the next lowest suitability score is given the second order weight, and so on. Applying order weights has the effect of weighting factors based on their rank from minimum to maximum value for each location. When ordered weights are the same, OWA creates a result that is identical to WLC. This indicates that WLC is a special case of OWA (Eastman 2012). In this research, the factor and order weights (Tables 5 and 6) were obtained from the AHP and WLC methods, respectively, as described above. This is how, three different OWA generated landslide susceptibility maps were produced (Fig. 16).

\section{Analysis of the results}

At first, the landslide susceptibility maps were evaluated qualitatively. It helps to select the most appropriate method of LSM for a particular area (Feizizadeh and Blaschke 2013). In the case of the AHP method, high susceptibility zones cover about $23 \%$ of the total area, while about $54 \%$ area was classified as medium susceptible, and the remaining $24 \%$ area was classified as low susceptible zone (Table 7). About 42, 20, and $2 \%$ areas fall within the high susceptible zone for the WLC_1, WLC_2, and WLC_3, respectively. Similarly, about 20,3 , and $1 \%$ areas were classified as high susceptible zones for the OWA_1, OWA_2, and OWA_3 methods, respectively (Table 7 ).

Then the accuracies of the landslide susceptibility maps were determined quantitatively. To do this, the landslide inventory map with the 20 known landslide events was compared with the respective susceptibility maps derived from the AHP, WLC, and OWA methods (Table 7). For the AHP method, the comparison shows that $100 \%$ of the known landslides fall into the high susceptibility zone. No known landslide event was observed in the remaining categories (Table 7). The comparisons showed that the high susceptibility zones covered exactly 100,100, and $90 \%$ of the known landslides for the WLC_1, WLC_2, and WLC_3, respectively. Lastly, the high susceptible zones covered 100, 90, and $45 \%$ of the known landslides for the OWA_1, OWA_2, and OWA_3 methods, respectively. In all the cases, no landslide was observed in the low susceptibility zones (Table 7).

High susceptibility zone covering $100 \%$ of known landslides does not always mean that the results are accurate. In some cases, high susceptibility zone occurred in the flat areas with moderate or mixed moderate soil permeability indicates that the results obtained using the MCDA methods also have some errors. MCDA methods are generally based on weighting the factor maps and finally overlaying those layers. As a result, any incorrect perception on the role of the different slope-failure criteria can be easily conveyed from the expert's opinion into the weight assignment (Kritikos and Davies 2011). This can cause errors in the final outputs. In this research, a total of 9 factor maps each with 5 classes were considered. It is difficult to assign criteria weights for all these sub-factors and develop a proper combination. Therefore, it is important to keep the factor map layers and their classes into reasonable numbers for getting better results. Errors can also occur due to incorrect pairwise comparisons between the criteria, classifying the factor maps and defining the susceptibility zones qualitatively. Moreover, there might be errors in the GIS/ remotely sensed datasets, problems while conducting questionnaire surveying for defining the weights, and taking the GPS values, etc. The main challenge of this kind of GISMCDA analyses is to keep the errors as less as possible. This can be achieved by defining the best combination of criteria weights.

AHP method uses pairwise comparison of each criterion, while WLC directly assigns the weights of relative importance to each attribute map layer and OWA involves two-step weighting (criterion and order weights). Each method follows 


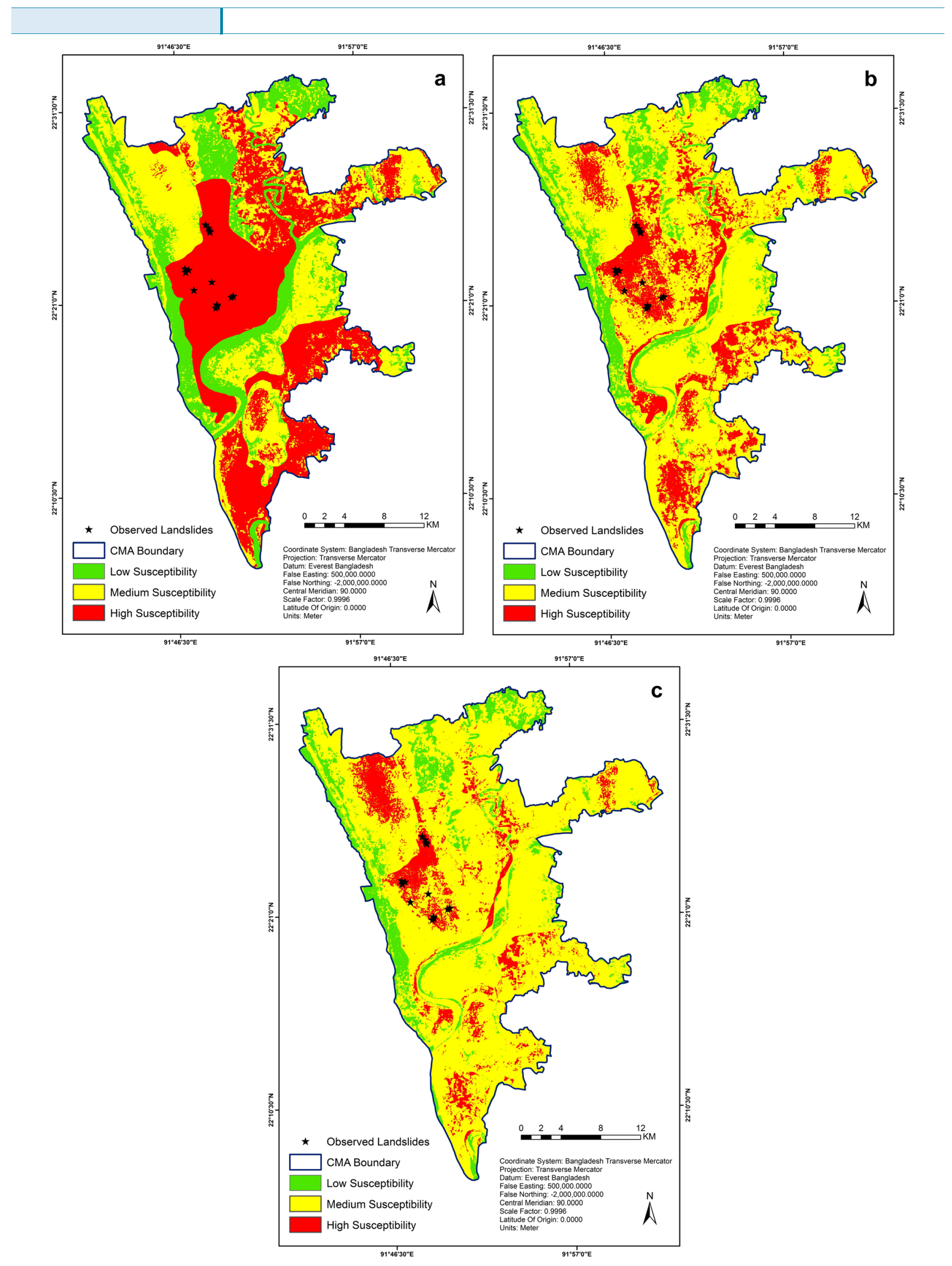

Fig. 15 Landslide susceptibility maps derived from a WLC_1, b WLC_2, and c WLC_3 method 
Table 5 Factor weights for OWA analysis

\begin{tabular}{|l|l|}
\hline (1) Distance to stream & 0.0190 \\
\hline (2) Distance to road & 0.0243 \\
\hline (3) Precipitation & 0.0366 \\
\hline (4) Distance to drain & 0.0469 \\
\hline (5) NDVI & 0.0706 \\
\hline (6) Land cover & 0.0975 \\
\hline (7) Elevation & 0.1989 \\
\hline (8) Slope & 0.1989 \\
\hline (9) Soil permeability & 0.3074 \\
\hline
\end{tabular}

its own way of assigning weights to factors or orders. Therefore, it is not possible to declare that one method is superior to other. As it is a trial and error/iterative process, the final output maps may give some errors as well. Still the MCDA methods give better accuracies, which are acceptable for producing real-world LSM in terms of landslide disaster risk reduction. Moreover, each MCDA method can produce different types of landslide susceptibility maps based on assigning different weights for the instability factors. The weights can be obtained through expert opinion surveying, or even it can be achieved from the participatory-based community surveying, or it can be a combination of both. Finally, it is the researcher's or policy makers' decision to choose the appropriate weighting combination and the output maps, as per the local context and research/project objectives.

\section{Validation of the methods}

In order to determine the statistical reliability of the results, it is important to perform validation of spatial results in a structured manner (Ahmed et al. 2013b). To do this validation, Relative Operating Characteristic (ROC) method was used in this research. The ROC analysis is useful for cases in which the scientist wants to see how well the suitability map portrays the location of a particular category, but does not have an estimate of the quantity of the category. For example, the ROC could be used to compare an image of modelled probability for landslides against an image of actual observed landslides (Eastman 2012). The area under ROC curves (AUC) constitutes one of the most common used accuracy statistics for the prediction models in natural hazard assessments (Ahmed and Rubel 2013). The minimum value of AUC is 0.5, which means no improvement over random assignment. The maximum value of AUC is 1 that denotes perfect discrimination (Nefeslioglu et al. 2008).

The comparison results are shown in Fig. 17 as a line graph (threshold type is equal interval and number of thresholds is $25 \%)$. The AUC values are indicating the accuracies of the methods used for LSM. The AUC values of the AHP, WLC_1, WLC_2, WLC_3, OWA_1, OWA_2, and OWA_3 methods were calculated as $0.898,0.839,0.911,0.885,0.904,0.951$, and 0.871 , respectively (Fig. 17). In general, the verification results showed satisfactory agreement between the susceptibility map produced and the observed landslide location map (AUC values ranged from 0.871 to 0.951 ). Finally, it can be stated that higher accuracy was found for all the MCDA methods applied. But the landslide susceptibility map produced by the OWA_2 method appeared to be slightly more accurate than those generated by applying the other methods (Fig. 17).

\section{Discussions and future research}

GIS-MCDA methods are based on the weighting of the factors and orders of the thematic layers. Therefore, the preferences of the decision makers play important role in producing the LSM. In this case, the factor/order weights should be assigned carefully after proper consultation with the relevant experts, local people, and communities at risk, and extensive field surveying is also required. From the analysis, it was evident that urbanized areas with very low soil permeability and steep slope were highly vulnerable to landslide hazards.

Till now, in all the cases, the researchers used the previous or existing land cover images to produce the landslide susceptibility maps. But land-use/land-cover maps can be treated

Table 6 Order weights for OWA analysis

\begin{tabular}{llllllllll}
$\begin{array}{l}\text { Order } \\
\text { weight }\end{array}$ & $\begin{array}{l}\text { Weight } \\
1\end{array}$ & $\begin{array}{l}\text { Weight } \\
2\end{array}$ & $\begin{array}{l}\text { Weight } \\
3\end{array}$ & $\begin{array}{l}\text { Weight } \\
4\end{array}$ & $\begin{array}{l}\text { Weight } \\
5\end{array}$ & $\begin{array}{l}\text { Weight } \\
6\end{array}$ & $\begin{array}{l}\text { Weight } \\
7\end{array}$ & $\begin{array}{l}\text { Weight } \\
8\end{array}$ & $\begin{array}{l}\text { Weight } \\
9\end{array}$ \\
\hline OWA_1 & 0.05 & 0.05 & 0.05 & 0.05 & 0.10 & 0.10 & 0.10 & 0.10 \\
\hline OWA_2 & 0.05 & 0.05 & 0.05 & 0.10 & 0.10 & 0.15 & 0.10 & 0.15 \\
\hline OWA_3 & 0.05 & 0.05 & 0.05 & 0.10 & 0.10 & 0.15 & 0.15 & 0.15 \\
\hline
\end{tabular}




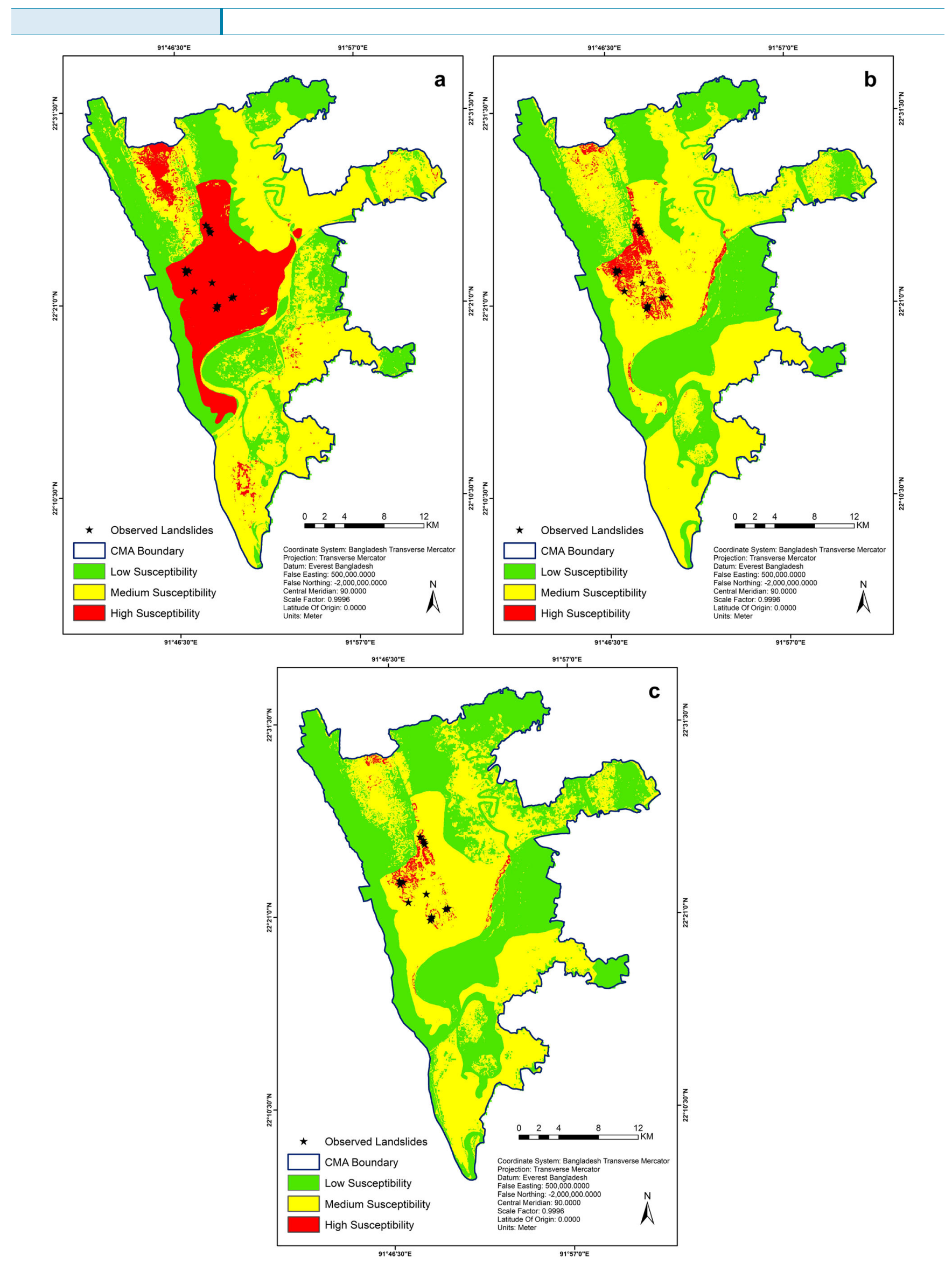

Fig. 16 Landslide susceptibility maps derived from a OWA_1, b OWA_2, and c OWA_3 method 


\section{Original Paper}

Table 7 Comparison of landslide susceptibility maps with the observed landslides

\begin{tabular}{|c|c|c|c|c|}
\hline Methods & Susceptible zones & Area under category (\%) & Number of landslides & Comparison with landslide area (\%) \\
\hline \multirow[t]{3}{*}{ AHP } & High susceptibility & 22.713 & 20 & 100 \\
\hline & Medium susceptibility & 53.609 & 0 & 0 \\
\hline & Low susceptibility & 23.677 & 0 & 0 \\
\hline \multirow[t]{3}{*}{ WLC_1 } & High susceptibility & 41.890 & 20 & 100 \\
\hline & Medium susceptibility & 36.791 & 0 & 0 \\
\hline & Low susceptibility & 21.319 & 0 & 0 \\
\hline \multirow[t]{3}{*}{ WLC_2 } & High susceptibility & 20.365 & 20 & 100 \\
\hline & Medium susceptibility & 66.079 & 0 & 0 \\
\hline & Low susceptibility & 13.556 & 0 & 0 \\
\hline \multirow[t]{3}{*}{ WLC_3 } & High susceptibility & 1.5520 & 18 & 90 \\
\hline & Medium susceptibility & 96.911 & 2 & 10 \\
\hline & Low susceptibility & 1.5370 & 0 & 0 \\
\hline \multirow[t]{3}{*}{ OWA_1 } & High susceptibility & 19.565 & 20 & 100 \\
\hline & Medium susceptibility & 46.149 & 0 & 0 \\
\hline & Low susceptibility & 34.286 & 0 & 0 \\
\hline \multirow[t]{3}{*}{ OWA_2 } & High susceptibility & 3.4750 & 18 & 90 \\
\hline & Medium susceptibility & 52.381 & 2 & 10 \\
\hline & Low susceptibility & 44.144 & 0 & 0 \\
\hline \multirow[t]{3}{*}{ OWA_3 } & High susceptibility & 1.3410 & 9 & 45 \\
\hline & Medium susceptibility & 46.115 & 11 & 55 \\
\hline & Low susceptibility & 52.544 & 0 & 0 \\
\hline
\end{tabular}

as a dynamic variable because within the next few decades, the land use of a particular area can be abruptly changed (e.g. CMA). This change in land use pattern (e.g. deforestation, hill-cutting) can put triggering impacts on occurring landslide hazards (Mugagga et al. 2012). Therefore, while modelling landslide hazard maps, it is very important to take into account a new thematic layer-'the future projected land cover map'.

Same thing can happen for the trend in precipitation pattern. It is already indicated that due to climate change, a

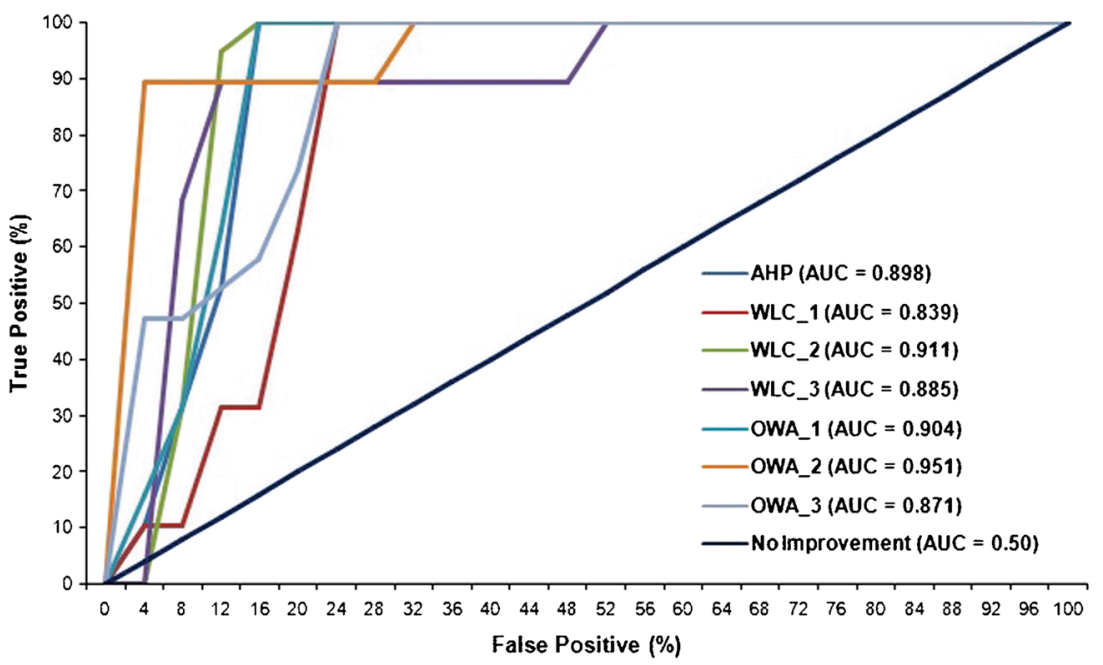

Fig. 17 Assessment of model performance based on the ROC curves 
significant increase in annual and pre-monsoon rainfall in Bangladesh is observed (Shahid 2011). Moreover, the recent landslide events were related to the extreme rainfall intensities within short period of time (Khan et al. 2012). Therefore, it is also important to consider future rainfall pattern while producing landslide susceptibility maps. These are the current research gaps in landslide susceptibility modelling.

In this drawback, future research should take into consideration the dynamic variables like the simulated land cover map and future rainfall pattern to predict the future landslide scenario in CMA. This will be a new kind of analysis and interesting outcomes are expected. It will help answering whether using the simulated dynamic variables will give better accuracy/results or not. It is also expected that preparing landslide hazard maps, using this kind of new modelling concept will add new knowledge to landslide susceptibility mapping in modern science. The flowchart of this new concept is depicted in Fig. 18.

On the other hand, the term 'Natural Disaster' refers to extreme natural events like tsunami, earthquakes, landslides, floods, cyclones, etc. But it has been argued that these events are not disasters until a vulnerable group of people is exposed (Wisner et al. 2003). Therefore, it is important to understand the underneath reasons for this progression of urban landslide vulnerability. It is also evident that even being aware of the landslide risks people are living in those risky areas. This situation needs to be taken into consideration. Just producing some automated hazard and susceptibility maps, using different scientific modelling techniques, cannot reduce the landslide risks. The vulnerability of the people at risk and human adaptation to landslides needs to be

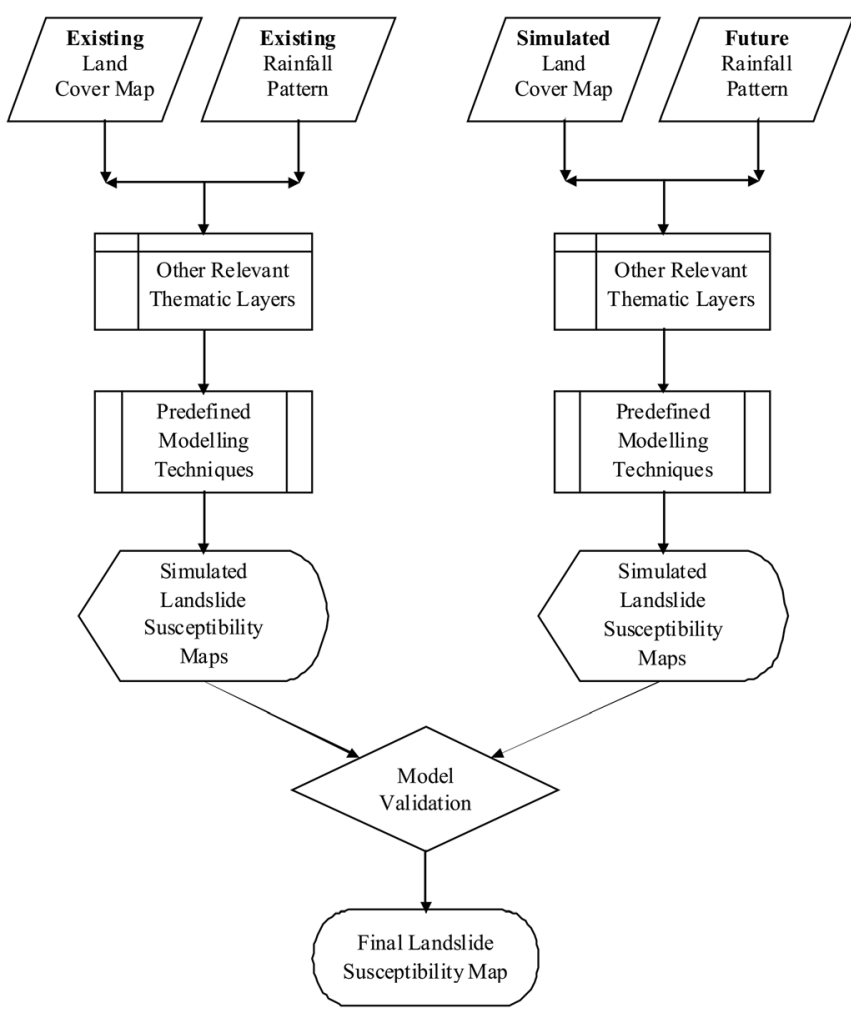

Fig. 18 Flowchart of the new concept for landslide susceptibility mapping analysed to address this problem properly (Alexander 2005; Alexander 2000).

\section{Conclusions}

Landslides are a common hazard in highly urbanized hilly areas in CMA, especially during the rainy season (Khan et al. 2012; Ahmed and Rubel 2013). Therefore, the aim of this research is to produce acceptable landslide susceptibility maps for CMA, so that appropriate landslide disaster mitigation strategies can be developed. In this research, three different GIS-MCDA methods-the AHP, WLC, and OWA-were applied to scientifically assess the landslide susceptible areas in CMA. Nine different thematic layers or landslide causative factors were considered. Then seven different landslide susceptibility scenarios were generated based on the three weighted overlay techniques.

Later, the performances of the MCDA methods were validated using the area under the ROC curves. The accuracy of the landslide susceptibility maps produced by the AHP, WLC_1, WLC_2, WLC_3, OWA_1, OWA_2, and OWA_3 methods were found as $89.80,83.90,91.10,88.50,90.40,95.10$, and $87.10 \%$, respectively. The verification results showed satisfactory agreement (Nefeslioglu et al. 2008; Feizizadeh and Blaschke 2013) between the susceptibility maps produced and the existing data on the 20 historical landslide locations. It is important to mention that due to the dynamic nature of the land use and precipitation patterns, the landslide susceptibility maps are subject to vary. Hence, these maps should be updated and modified, time-to-time.

The preparation of landslide susceptibility map is the first step towards the reduction of landslide hazard. But it is also important to create awareness among the local people based on the predictive landslide susceptibility maps. Moreover, developing early warning system, increasing cooperation among different public/autonomous/non-governmental organizations, launching public awareness campaign, arranging relevant seminars and workshops, and generating facilities for proper evacuation system in crisis moments are highly recommended.

The outcome of this research shall help the endangered local inhabitants/communities, urban planners, and engineers to reduce losses caused by existing and future landslides by means of prevention, mitigation, and avoidance. The results will also be useful for explaining the driving factors of the known historical landslides, for supporting emergency decisions, and for upholding the efforts on the mitigation of future landslide hazards in CMA, Bangladesh.

\section{Acknowledgements}

Bayes Ahmed is a Commonwealth Scholar funded by the UK government. The author is grateful to the IRDR, UCL, International Centre for Integrated Mountain Development (ICIMOD), the Association of American Geographers (AAG), Chittagong University of Engineering and Technology (CUET), Professor Dr. David E. Alexander, Yiaser Arafat Rubel, Renato Forte, Kabir Uddin, Debasish Roy Raja, Rashed Jalal Himal, the relevant $\mathrm{CDA}$ officials, and the people of the landslide 
vulnerable areas who helped in numerous occasions. This article is a part of the $\mathrm{PhD}$ thesis that is being conducted by the corresponding author at IRDR, UCL. Finally, the author would like to thank the anonymous reviewers and the editorial board of the 'Landslides' journal for their constructive comments that improved the quality of the manuscript.

Open Access This article is distributed under the terms of the Creative Commons Attribution License which permits any use, distribution, and reproduction in any medium, provided the original author(s) and the source are credited.

\section{References}

Ahammad R (2009) Understanding institutional changes for reducing social vulnerability to landslides in Chittagong City, Bangladesh. Dissertation, Stockholm University, Sweden

Ahmed B, Ahmed R (2012) Modeling urban land cover growth dynamics using multitemporal satellite images: a case study of Dhaka, Bangladesh. ISPRS Int J Geo-Inf 1:3-31

Ahmed B, Rubel YA (2013) Understanding the issues involved in urban landslide vulnerability in Chittagong metropolitan area, Bangladesh. The Association of American Geographers (AAG). https://sites.google.com/a/aag.org/mycoe-servirglobal/finalarafat. Assessed 17 January 2014

Ahmed B, Kamruzzaman M, Zhu X, Rahman MS, Choi K (2013a) Simulating land cover changes and their impacts on land surface temperature in Dhaka, Bangladesh. Remote Sens 5:5969-5998

Ahmed B, Ahmed R, Zhu X (2013b) Evaluation of model validation techniques in land cover dynamics. ISPRS Int J Geo-Inf 2:577-597

Akbar TA, Ha SR (2011) Landslide hazard zoning along Himalayan Kaghan Valley of Pakistan - by integration of GPS, GIS, and remote sensing technology. Landslides 8(4):527-540

Alexander DE (2000) Confronting catastrophe: new perspectives on natural disasters. Oxford University Press, UK

Alexander D (2005) Vulnerability to landslides. In: Glade T, Anderson MG, Crozier MJ (eds) Landslide hazard and risk, front matter. Wiley, Chichester, pp 175-198. doi:10.1002/9780470012659.fmatter

ArcGIS ${ }^{\circledR} 10$ Help (2012) Environmental Systems Research Institute (ESRI). Redlands, CA, USA. http://help.arcgis.com/en/arcgisdesktop/10.0/help/. Accessed 7 November 2013

Avtar R, Singh CK, Singh G, Verma RL, Mukherje S, Sawada H (2011) Landslide susceptibility zonation study using remote sensing and GIS technology in the KenBetwa River Link area, India. Bull Eng Geol Environ 70:595-606

Ayala IA, Chavez OE, Parrot JF (2006) Landsliding related to land-cover change: a diachronic analysis of hillslope instability distribution in the Sierra Norte, Puebla, Mexico. Catena 65:152-165

Bai SB, Wang J, Lü GN, Zhou PG, Hou SS, Xu SN (2010) GIS-based logistic regression for landslide susceptibility mapping of the Zhongxian segment in the Three Gorges area, China. Geomorphology 115:23-31

Bui DT, Pradhan B, Lofman 0, Revhaug I, Dick ØB (2013) Regional prediction of landslide hazard using probability analysis of intense rainfall in the Hoa Binh province, Vietnam. Nat Hazards 66:707-730

Chowdhury SQ (2012) Chittagong City. In: Islam N (ed) Banglapedia, National Encyclopaedia of Bangladesh, 2nd edn. Banglapedia Trust, Asiatic Society of Bangladesh, Dhaka, Bangladesh. http://www.bpedia.org/C_0215.php. Assessed 14 September 2013

Community Report, Chittagong Zila (2012) Population and Housing Census 2011, Bangladesh Bureau of Statistics, Statistics and Informatics Division, Ministry of Planning, Dhaka, Bangladesh

Comprehensive Disaster Management Programme-II (2012) Landslide Inventory \& Land-use Mapping, DEM Preparation, Precipitation Threshold Value \& Establishment of Early Warning Devices. Ministry of Food and Disaster Management, Disaster Management and Relief Division, Government of the People's Republic of Bangladesh

Duman TY, Can T, Emre 0, Kecer M, Dogan A, Ates S, Durmaz S (2005) Landslide inventory of north-western Anatolia, Turkey. Eng Geol 77:99-114
Eastman R (2012) The IDRISI Selva Help. Clark Labs, Clark University 950 Main Street, Worcester MA 01610-1477 USA

Eastman JR, Jiang H (1996) Fuzzy measures in multi-criteria evaluation. In: Proceedings at the Second International Symposium on Spatial Accuracy Assessment in Natural Resources and Environmental Studies, May 21-23, Fort Collins, Colorado, 527-534.

Feizizadeh B, Blaschke T (2013) GIS-multicriteria decision analysis for landslide susceptibility mapping: comparing three methods for the Urmialake basin, Iran. Nat Hazards 65:2105-2128

Godt JW, Baum RL, Savage WZ, Salciarini D, Schulz WH, Harp EL (2008) Transient deterministic shallow landslide modeling: Requirements for susceptibility and hazard assessment in a GIS framework. Eng Geol 102:214-226

Guzzetti F, Carrara A, Cardinali M, Reichenbach P (1999) Landslide hazard evaluation: a review of current techniques and their application in a multi-scale study, Central Italy. Geomorphology 31:181-216

Isik Yilmaz I (2009) Landslide susceptibility mapping using frequency ratio, logistic regression, artificial neural networks and their comparison: a case study from Kat landslides (Tokat-Turkey). Comput Geosci 35:1125-1138

Islam MS (2012) Seven Soil Tracts. In: Islam N (ed) Banglapedia, National Encyclopaedia of Bangladesh, 2nd edn. Banglapedia Trust, Asiatic Society of Bangladesh, Dhaka, Bangladesh. http://www.banglapedia.org/HT/S_0251.htm. Assessed 18 June 2014

Jiang H, Eastman JR (2000) Application of fuzzy measures in multi-criteria evaluation in GIS. Int J Geogr Inform Sci 14:173-184

Karsli F, Atasoy M, Yalcin A, Reis S, Demir 0, Gokceoglu C (2009) Effects of land-use changes on landslides in a landslide-prone area (Ardesen, Rize, NE Turkey). Environ Monit Assess 156:241-255

Kavzoglu T, Sahin EK, Colkesen I (2013) Landslide susceptibility mapping using GIS-based multi-criteria decision analysis, support vector machines, and logistic regression. Landslides. doi:10.1007/s10346-013-0391-7

Kayastha P, Dhital MR, Smedt FD (2012) Landslide susceptibility mapping using the weight of evidence method in the Tinau watershed, Nepal. Nat Hazards 63:479-498

Khan YA, Lateh H, Baten MA, Kamil AA (2012) Critical antecedent rainfall conditions for shallow landslides in Chittagong City of Bangladesh. Environ Earth Sci 67(1):97-106

Kritikos T, Davies TRH (2011) GIS-based Multi-Criteria Decision Analysis for landslide susceptibility mapping at northern Evia, Greece. Z dt Ges Geowiss 162:421-434

Lee S, Sambath T (2006) Landslide susceptibility mapping in the Damrei Romel area, Cambodia using frequency ratio and logistic regression models. Environ Geol 50:847-855

Malczewski J (2004) GIS-based land-use suitability analysis: a critical overview. Prog Plan 62:3-65

Mangiza NDM, Arimah BC, Jensen I, Yemeru EA, Kinyanjui MK (2011) Cities and climate change: global report on human settlements, 2011, United Nations Human Settlements Programme (UN-Habitat), Nairobi, Kenya

Mugagga F, Kakembo V, Buyinza M (2012) Land use changes on the slopes of Mount Elgon and the implications for the occurrence of landslides. Catena 90:39-46

Nefeslioglu HA, Gokceoglu C, Sonmez H (2008) An assessment on the use of logistic regression and artificial neural networks with different sampling strategies for the preparation of landslide susceptibility maps. Eng Geol 97:171-191

Park S, Choi C, Kim B, Kim J (2013) Landslide susceptibility mapping using frequency ratio, analytic hierarchy process, logistic regression, and artificial neural network methods at the Inje area, Korea. Environ Earth Sci 68:1443-1464

Persits FM, Wandrey CJ, Milici RC, Manwar A (2001) Digital Geologic and Geophysical Data of Bangladesh. The U.S. Geological Survey Open File Report 97-470H (CD-ROM). http://pubs.usgs.gov/of/1997/ofr-97-470/OF97-470H/. Assessed 18 November 2013

Poudyal CP, Chang C, Oh HJ, Lee S (2010) Landslide susceptibility maps comparing frequency ratio and artificial neural networks: a case study from the Nepal Himalaya. Environ Earth Sci 61:1049-1064

Rajakumar R, Sanjeevi S, Jayaseelan S, Isakkipandian G, Edwin M, Balaji P, Ehanthalingam $G$ (2007) Landslide susceptibility mapping in a hilly terrain using remote sensing and GIS. J Indian Soc Remote Sensing 35(1):31-42

Saaty TL (1977) A scaling method for priorities in hierarchical structures. J Math Psychol 15:231-281

Shahid S (2011) Trends in extreme rainfall events of Bangladesh. Theor Appl Climatol 104:489-499 
Tachikawa T, Hato M, Kaku M, Iwasaki A (2011) The characteristics of ASTER GDEM version 2, IGARSS. http://www.jspacesystems.or.jp/ersdac/GDEM/E/1.html. Assessed 23 October 2013

Uddin K (2013) Image classification: hands on exercise using eCognition. eCognition Community, Trimble Geospatial Imaging, Arnulfstrasse 126, 80636 Munich, Germany

Wisner B, Blaikie P, Cannon T, Davis I (2003) At Risk: Natural Hazards, People's Vulnerability and Disasters. Routledge, New York, USA

Yager RR (1988) On ordered weighted averaging aggregation operators in multicriteria decision making. IEEE Trans Syst Man Cybern 8:183-190

Yilmaz I, Yildirim M (2006) Structural and geomorphological aspects of the Kat landslides (Tokat-Turkey), and susceptibility mapping by means of GIS. Environ Geol 50(4):461-472
Zêzere JK, Garcia RAC, Oliveira SC, Reis E (2008) Probabilistic landslide risk analysis considering direct costs in the area north of Lisbon (Portugal). Geomorphology 94:467-495

\section{B. Ahmed ( $)$}

Institute for Risk and Disaster Reduction (IRDR), Department of Earth Sciences, University College London (UCL),

Gower Street, London, WC1E 6BT, United Kingdom (UK)

e-mail: bayes.ahmed.13@ucl.ac.uk 